\title{
Advanced Thin Film Cathodes for Lithium Ion Batteries
}

\author{
Zhimin $\mathrm{Qi}^{1}$ and Haiyan Wang ${ }^{1,2}$ \\ ${ }^{1}$ School of Materials Engineering, Purdue University, West Lafayette, IN 47907, USA \\ ${ }^{2}$ School of Electrical and Computer Engineering, Purdue University, West Lafayette, Indiana 47907, USA \\ Correspondence should be addressed to Haiyan Wang; hwang00@purdue.edu
}

Received 18 July 2019; Accepted 28 November 2019; Published 6 February 2020

Copyright @ 2020 Zhimin Qi and Haiyan Wang. Exclusive Licensee Science and Technology Review Publishing House. Distributed under a Creative Commons Attribution License (CC BY 4.0).

\begin{abstract}
Binder-free thin film cathodes have become a critical basis for advanced high-performance lithium ion batteries for lightweight device applications such as all-solid-state batteries, portable electronics, and flexible electronics. However, these thin film electrodes generally require modifications to improve the electrochemical performance. This overview summarizes the current modification approaches on thin film cathodes, where the approaches can be classified as single-phase nanostructure designs and multiphase nanocomposite designs. Recent representative advancements of different modification approaches are also highlighted. Besides, this review discusses the existing challenges regarding the thin film cathodes. The review also discusses the future research directions and needs towards future advancement in thin film cathode designs for energy storage needs in advanced portable and personal electronics.
\end{abstract}

\section{Introduction}

Lithium ion batteries have attracted great research interests in the past few decades since the first commercialized lithium ion battery demonstration by SONY in 1990 due to its unmatchable energy and power density and its applications ranging from portable electronics to hybrid/full electric vehicles [1]. Extensive research efforts have been mostly focused on cathode material modification for advanced high performance lithium ion batteries as the cathode performance limits the cell potential and capacity of current lithium ion batteries $[2,3]$. For example, olivine-type $\mathrm{LiFePO}_{4}$ has excellent structural stability but suffers sluggish kinetics [4], the layered-type $\mathrm{LiCoO}_{2}$ has low thermal stability and spineltype $\mathrm{LiMn}_{2} \mathrm{O}_{4}$ suffers from bad cycling performance [5-8]. Efforts have been devoted to solve these issues, such as carbon coating [9-11], reduced particle dimensions [12], elemental dopings [13], modified chemistry [14], composite design [15], and nanostructure designs [16]. However, most of these works were performed using classical thick film electrodes processed by slurry-based approaches, which contain inactive materials that decrease the energy density of the cells and complicate the fundamental studies.

To overcome the issues brought by the inactive materials in the cathodes, binder-free thin film cathodes emerged, reported by Bates et al. in 1993 using RF magnetron sputter- ing [17]. This approach can eliminate the weight of inactive materials, which effectively increase the energy loading in the cell. Furthermore, the binder-free cathodes can avoid the usage of toxic solvent N-methyl-2-pyrrolidone (NMP) during the electrode processing. In terms of the cathode film thickness, it has been generally reported between several nanometers to a few micrometers for thin film cathodes in order to decrease the charge diffusion length, which makes the pristine cathode materials functional even without conductive additives and enables high power applications. Thin film cathodes can also be easily adopted for all-solid-state batteries where no flammable liquid electrolyte is used and enables dedicated applications such as implanted medical devices, flexible and portable electronics, smart cards. Additionally, thin film cathodes also take advantage of the fact that they are free of inactive additives and can be designed to achieve different microstructures or crystalline structures by various thin film techniques and are easier to explore than slurry cathodes [18].

The potential versus specific capacity plot in Figure 1 summarizes the reported up-to-date thin film cathode materials. As shown, most of the studied systems are model cathodes from different structure classes (i.e., olivine- $\mathrm{LiFePO}_{4}$, layered- $\mathrm{LiCoO}_{2} / \mathrm{V}_{2} \mathrm{O}_{5}$, and spinel- $\mathrm{LiMn}_{2} \mathrm{O}_{4}$ ). It is worth noting that several low potential materials are also plotted and are considered cathode materials due to their applications 


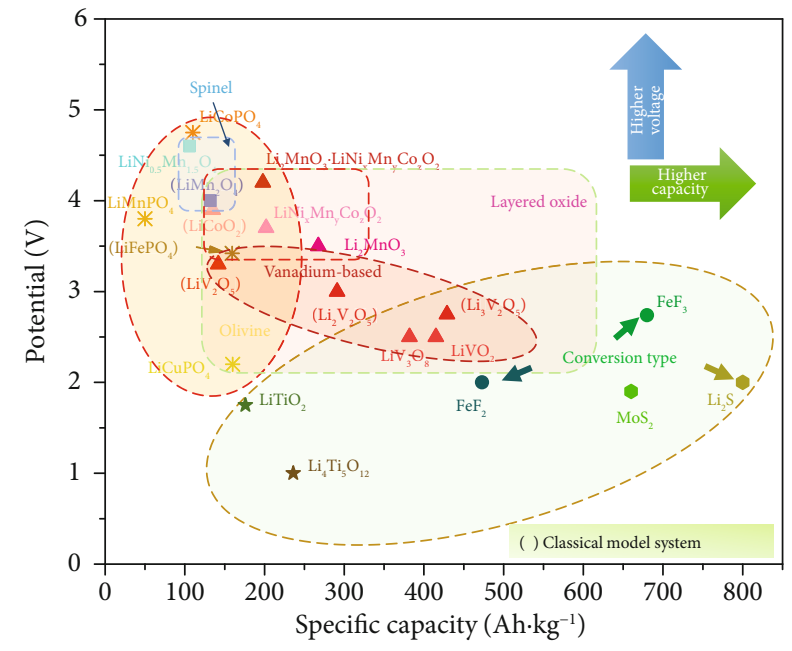

Figure 1: Potential versus capacity plot of the most studied cathode materials using thin film techniques.

in certain $2 \mathrm{~V}$ batteries. In addition, layered oxides should be the more suitable choices for ideal cathode materials as they have higher voltage and higher specific capacity [19]. The review reports examples from these model cathode systems for the purpose of introducing various modification methods. The review focuses on "binder-free" cathodes using thin film processing techniques and presents several representative examples using different modification methods to demonstrate the thin film modification approaches and progresses. At the end of the review, future research directions and potentials are discussed.

\section{Overview of Modification Approaches for Thin Film Cathodes}

Thin film cathode modification techniques can be categorized into two major groups, i.e., single-phase nanostructured cathodes and multiphase nanocomposite cathodes. The principal thin film techniques to achieve the abovementioned modifications include but are not limited to sol-gel method $[20,21]$, hydrothermal synthesis [22], coprecipitation [23], template-assisted synthesis [24], electrostatic spray deposition (EDS) [25], atomic layer deposition [26], laser processing [27], chemical vapor deposition [28], physical vapor deposition [29], plasma-assisted synthesis [30], etc. The detailed methodologies, shown in Figure 2, can be further divided as follows: (A1) to design nanostructured thin film cathodes on planar substrates with different morphologies to increase surface area; (A2) to design hierarchical nanostructured films on prenanostructured substrates where the surface areas can be further increased than the simple nanostructured thin films on planar substrates; (B) to apply laser structuring technique for posttreatment on grown thin film cathodes to achieve advanced nanostructures for larger surface area and better performance; (C1) to apply surface coatings on the grown thin film cathodes, which can also be combined with nanostructured thin film electrodes; and (C2) to achieve cogrown nano- composite thin film cathodes for property compensation where the morphology of the secondary phase can be controlled for various designed performance.

\section{Thin Film Electrode Modifications}

3.1. Nanostructure Design (Single Phase). Despite the advantages of the additive-free thin film cathodes mentioned above [31], the thin film cathodes have limited energy loading due to constraint electrodes footprint [32]. In order to solve this issue, it is necessary to increase the surface area of electrodes and harvest from 3D structures instead of planar 2D structures, which can increase the loading of active materials as well as the kinetics of electrodes [33]. Different modification approaches to achieve such a goal are introduced and discussed below.

3.1.1. Nanostructured Thin Film Electrodes (a Bottom-Up Method). This method refers to cathode thin films with nanostructured designs, also known as 3D cathode electrodes, on flat surface substrates. The schematic drawing is presented in Figure 3. Regarding this approach, the electrochemical performance can be tuned mainly through the different morphologies of the nanostructured designs.

(1) Nanorod, Nanoneedle, and Nanowire Film Morphologies. Physical Vapor Deposition Synthesis. Nanorod/needle-like morphology thin films of olivine-type $\mathrm{LiFePO}_{4}$ were reported by Sun et al. [34] using an oblique angle pulsed laser deposition (OAPLD) technique, which is simply to create a nonzero source-to-substrate angle and introduce a shadowing effect to form the isolated nanorod morphology. The method presented a slight improvement in performance compared to planar films [35]. Upon using the same OAPLD technique, $\mathrm{Li}_{2} \mathrm{MnO}_{3}$ thin film, a highly insulating material [36], with tilted columnar morphology has been processed and significantly improved electrochemical performance was demonstrated [37]. The film with a thickness of $150 \mathrm{~nm}$ was grown on Au-buffered stainless steel substrates, which gives $267.46 \mathrm{mAh} \mathrm{g}^{-1}$ initial capacity $\left(99.5 \mu \mathrm{Ah} \mathrm{cm}^{-2} \mu \mathrm{m}^{-1}\right)$ and $80 \%$ capacity retention (equal to $2 \times 10^{-1} \%$ capacity loss per cycle) at $0.4 \mathrm{C}$ for 100 cycles, as well as a satisfying rate performance with $147.84 \mathrm{mAhg}^{-1}\left(55 \mu \mathrm{Ah} \mathrm{cm}^{-2} \mu \mathrm{m}^{-1}\right)$ at $9.3 \mathrm{C}$. The electrochemical performance was improved and a higher amount of active material loading was demonstrated when compared with other reports [38-40]. The work suggests that pulsed laser deposition is an easy one-step method for introducing advanced film morphologies and complicated film compositions designs.

Wet Chemical Synthesis. $\mathrm{LiCoO}_{2}$ was explored by Xia et al. [41] using a two-step hydrothermal synthesis. This approach first grew self-supported $\mathrm{Co}_{3} \mathrm{O}_{4}$ nanowire arrays on Au substrates and then applied hydrothermal lithiation to achieve the lithiated $\mathrm{LiCoO}_{2}$ under two different temperatures, which are high temperature layered-phase $\mathrm{LiCoO}_{2}$ and low temperature spinel-phase $\mathrm{LiCoO}_{2}$ (HT-LCO and LT-LCO). The synthesized HT-LCO exhibits a hierarchical architecture where the nanowires consist of small head-to- 


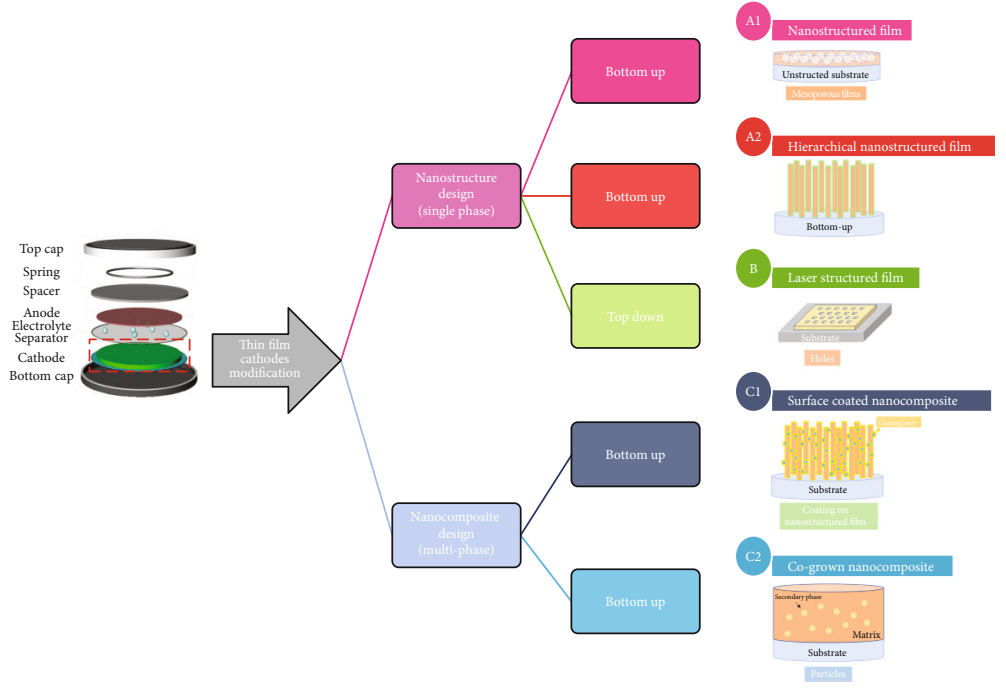

FIGURE 2: Summary of various modification approaches for cathode electrodes using thin film techniques: (A1) nanostructured cathode thin films on flat substrates; (A2) nanostructured cathode thin films on nanostructured substrates; (B) laser structured cathode thin films; (C1) cathode thin films with surface coating; (C2) multiphase nanocomposite cathode thin films.

$\mathrm{A} 1$ Nanostructured film

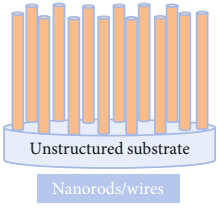

(a)

Unstructured substrate
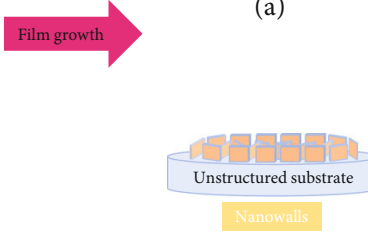

(c)

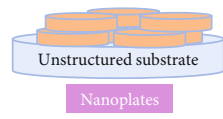

(b)

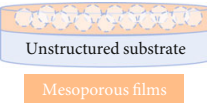

(d)

FIGURE 3: Schematic drawing of thin film modification approaches wherein nanostructured thin film cathode with different morphologies is directly grown on planar substrates.

head-connected LCO nanorods. This advanced structure shows a large areal capacity of $270 \mu \mathrm{Ah} \mathrm{cm}^{-2}$ and a gravimetric capacity of $135 \mathrm{mAhg}^{-1}$. Furthermore, HT-LCO also retains its morphology after a cycling test and keeps $90 \%$ capacity retention for 50 cycles (equivalent to $2 \times 10^{-1} \%$ capacity loss per cycle) at $0.1 \mathrm{C}$. As to rate performance, it can deliver about $103 \mathrm{mAh} \mathrm{g}^{-1}$ at $10 \mathrm{C}$, which is about $76 \%$ of that at $0.1 \mathrm{C}$. This two-step hydrothermal synthesis method proposes a facile technique for 3D cathode materials that are difficult to be directly synthesized. However, the chemical lithiation process could be problematic due to the potentially time-consuming and incomplete phase transformation process. In this regard, $\mathrm{V}_{2} \mathrm{O}_{5}$ cathodes could be better choices due to the simplicity of synthesizing the nonlithiated phases, and many studies of growing $\mathrm{V}_{2} \mathrm{O}_{5}$ nanowires/nanorods thin film electrodes have been reported [42-44].

(2) Mesoporous Film Morphologies. Mesoporous film morphologies are widely explored as it is one of the most effective film morphologies with increased surface area and can be applied to different material systems with various thin film techniques.

Electrostatic Spray Deposition Synthesis. This is a widely applied technique for porous thin films as it is suitable to grow films with porous nature. During the synthesis, the precursor droplets arrive at the substrates when they are still wet and lead to simultaneous spread of droplets and evaporation of 


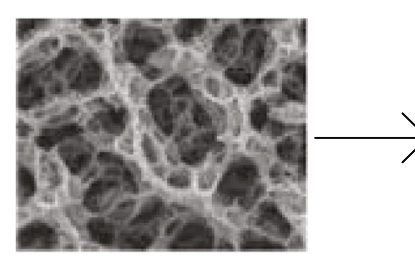

Layers of 2D reticular structure

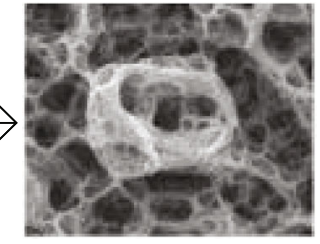

2D-3D mixed structure

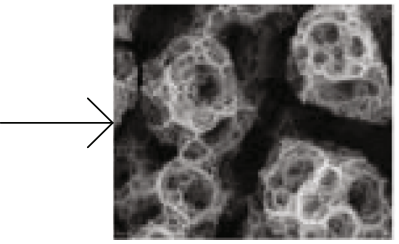

3D porous multideck-cage structure

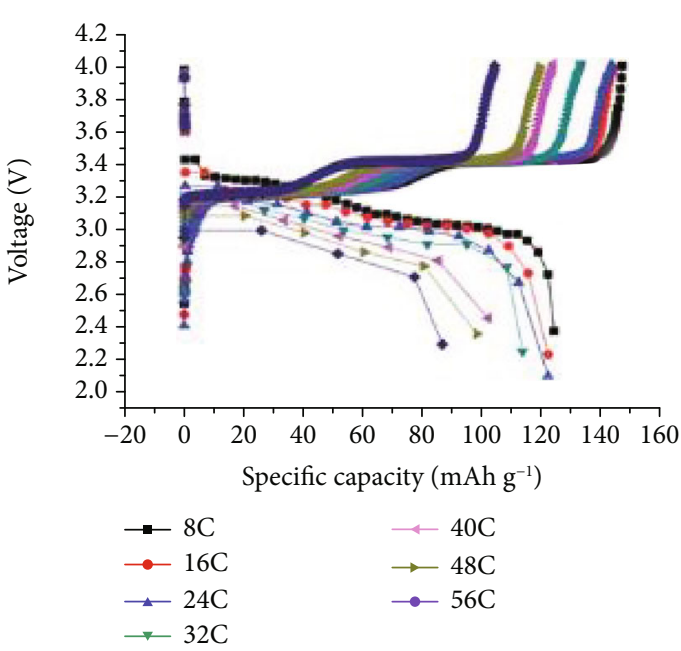

(b)

(a)

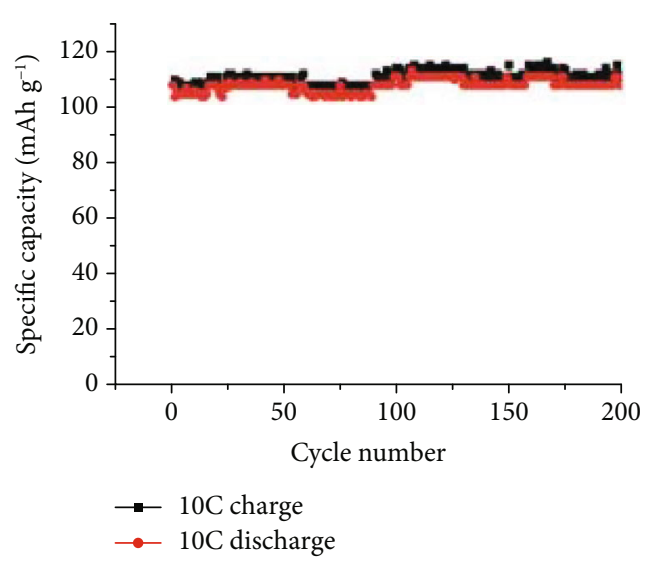

(c)

FIgURE 4: (a) The process of how the 3D porous multideck-cage structure is formed from the 2D reticular structure with increased layers. (b) Rate performance of $3 \mathrm{D}$ porous multideck-cage structure at $8 \mathrm{C}, 16 \mathrm{C}, 24 \mathrm{C}, 32 \mathrm{C}, 40 \mathrm{C}, 48 \mathrm{C}$, and $56 \mathrm{C}$. (c) Cycling performance for 200 cycles at $10 \mathrm{C}[52]$.

solvent, forming porous structures [45]. Furthermore, the morphologies can still be tuned by altering synthesis parameters, and it can be applied on multiple cathode systems [46-49].

Spinel-Type Cathode Systems. Shui et al. [50] synthesized and compared sponge-like porous, fractal-like porous, and dense $\mathrm{LiMn}_{2} \mathrm{O}_{4}$ thin films on Pt foils, which turned out to be the mesoporous sponge-like films with the highest surface area demonstrating the best performance with $120 \mathrm{mAh} \mathrm{g}^{-1}$ at $0.5 \mathrm{C}$ and $62.4 \mathrm{mAh} \mathrm{g}^{-1}$ at $10 \mathrm{C}$. Lafont et al. [51] also studied $\mathrm{LiNi}_{0.5} \mathrm{Mn}_{1.5} \mathrm{O}_{4}$ and further explored the effect of solvent towards film morphologies and grain coarsening under annealing.

Layered-Type Cathode Systems. Koike and Tatsumi [53] compared porous spinel phase LT-LCO and layered phase HT-LCO and reached a similar conclusion to Xia et al.'s report [41]. The layered HT-LCO has better electrochemical performance with a capacity of $140 \mathrm{mAh} \mathrm{g}^{-1}$ at a rate of $1 \mathrm{C}$ and $93 \%$ capacity retention for 100 cycles (equal to $9 \times 10$ ${ }^{-2} \%$ capacity loss per cycle) at $1 \mathrm{C}$. Wang et al. [52] reported $3 \mathrm{D}$ porous $\mathrm{V}_{2} \mathrm{O}_{5}$ nanoparticles with "multideck cage" morphology on stainless steel substrates. As seen in Figure 4(a), confirmed by EDS, the $2 \mathrm{D}$ reticular structure, 2D-3D mixed structure, and $3 \mathrm{D}$ porous multideck cage structure were obtained sequentially simply by increasing the deposition time. This structure exhibits an excellent rate performance shown in Figure 4(b); i.e., the gravimetric capacity of the film is $142 \mathrm{mAh} \mathrm{g}^{-1}$ at $0.5 \mathrm{C}$ and $86.7 \mathrm{mAh} \mathrm{g}^{-1}$ at $56 \mathrm{C}$ under volt- age window between $2.5 \mathrm{~V}$ and $4.0 \mathrm{~V}$ (corresponding to one $\mathrm{Li}$ intercalation). With respect to cycling performance, the film shows no virtual capacity loss for 200 cycles. The group also explored $3 \mathrm{D}$ porous $\mathrm{Fe}_{0.1} \mathrm{~V}_{2} \mathrm{O}_{5.15}$ thin films using ESD with enhanced cyclability, suggesting the potential of obtaining complicated film compositions with controlled morphologies for cathodes using EDS.

Template-Assisted Synthesis. Recently, a templated sol-gel method was used to synthesize $\mathrm{LiFePO}_{4}$ mesoporous thin films on $\mathrm{Pt} / \mathrm{Si}$ substrates [54]. Mosa et al. mixed polyisobutylene-block-poly(ethylene oxide) (PBI-b-PEO) amphiphilic block copolymer with $\mathrm{LiFePO}_{4}$ sol-gel precursors solution, which was later transferred onto substrates using dip coating to produce composite films, after which the copolymers were removed by thermal treatment to achieve the desired porous film morphology. The assembled cells show excellent electrochemical performance with a volumetric capacity of $40 \mu \mathrm{Ah} \mathrm{cm}^{-2} \mu \mathrm{m}^{-1}$ (gravimetric capacity of $159 \mathrm{mAh} \mathrm{g}^{-1}$ ) at $1.5 \mathrm{C}$ and $38.5 \mu \mathrm{Ah} \mathrm{cm}^{-2} \mu \mathrm{m}^{-1}$ at $7.5 \mathrm{C}$. The cells can be cycled at $1.5 \mathrm{C}$ with an initial gravimetric capacity of $159.43 \mathrm{mAh} \mathrm{g}^{-1}$ and $9 \times 10^{-4} \%$ capacity loss per cycle, as well as a high average coulombic efficiency of $99.5 \%$. Furthermore, the films experienced minor structural degradation despite the fact that $\mathrm{LiFePO}_{4}$ went through relatively large volume change during cycling [55], which is because the nanostructure is internally connected among pores, providing good structural stability [56]. Park et al. [57] also used a 
templated synthesis method on $\mathrm{LiMn}_{2} \mathrm{O}_{4}$ thin films with enhanced performance. However, the improvement is not as significant as Mosa et al.'s report on $\mathrm{LiFePO}_{4}$ [54]. Despite different physical properties of different cathodes, the performance could also be from the different templates used. Regarding $\mathrm{LiFePO}_{4}$, PBI- $b$-PEO precursors were mixed with $\mathrm{LiFePO}_{4}$ precursors first at an atomic level; then $\mathrm{PBI}-b-\mathrm{PEO} / \mathrm{LiFePO}_{4}$ composite films were deposited, whereas $\mathrm{LiMn}_{2} \mathrm{O}_{4}$ thin films were coated on arranged insoluble polystyrene (PS) microspheres on substrates. This indicates that synthesis methods with reactions at a finer scale should lead to better performance; for example, electrodes synthesized using the sol-gel method are expected to have better electrochemical performance than that by solid-state reactions [58].

(3) Other Film Morphologies. Electrodeposition Synthesis. Other than porous film morphologies and nanorod/pillar morphologies, several other novel film morphologies were also explored. Yu et al. [59] applied sol-gel combined anodic electrodeposition methods and grew mica-like $\mathrm{V}_{2} \mathrm{O}_{5}$ thin films. The electrodes exhibit a good cyclic performance with an initial capacity of $620 \mathrm{mAh} \mathrm{g}^{-1}$ (vs. $\mathrm{Ag} / \mathrm{AgCl}$ ) losing about $4.8 \times 10^{-1} \%$ capacity per cycle for 50 cycles at $4.6 \mathrm{C}$ and the morphology sustains. Xia et al. [60] applied the similar combined method for mesoporous $\mathrm{LiMn}_{2} \mathrm{O}_{4}$ nanowall arrays. They first deposited $\mathrm{Mn}_{3} \mathrm{O}_{4}$ seeds onto Au substrates using cathodic deposition techniques, then they achieved desired $\mathrm{LiMn}_{2} \mathrm{O}_{4}$ composition through chemical lithiation. It shows a $131.8 \mathrm{mAh} \mathrm{g}^{-1}$ gravimetric capacity at $1 \mathrm{C}$ and $97.1 \mathrm{mAh} \mathrm{g}^{-}$ ${ }^{1}$ at $20 \mathrm{C}$, and the cycling performance is satisfying with only $4 \times 10^{-2} \%$ capacity loss per cycle for 200 cycles. This advanced 3D morphology exhibits better structural stability and electrochemical performance than the previously discussed mesoporous $\mathrm{LiMn}_{2} \mathrm{O}_{4}$ thin films due to more stable building blocks.

Despite various synthesis techniques or film morphologies, in general, synthesis methods that engage atomic level reactions can lead to finer structures and better performances, and morphologies with an interconnected network are usually superior in structural stability. In addition, not specified above, postdeposition thermal treatment is generally required for better electrochemical performance as it ensures crystallinity and films adhesion with substrates.

\subsubsection{Hierarchical Nanostructured Thin Film Electrodes} (a Bottom-Up Method). Slightly different from the abovementioned section ("nanostructured film design"), this section refers to film depositions on substrates with nanostructured surfaces. As it is summarized in Figure 5, the substrates can be classified as poststructured substrates (patterned substrates) and as-prepared substrates (conductive paper/foam), and poststructured substrates can be further divided into "top-down" and "bottom-up" modified flat surface substrates. In addition to nanostructured substrates, thin films can be deposited onto the substrates surfaces through either conformal film depositions or nanostructured film depositions, where the latter is also referred to a hierarchical film architecture design. These methods usually grant more design possibilities and often provide better electrochemical performance due to better utilization of the limited substrates footprints with more sophisticated structures.

(1) Nanostructured Substrates Obtained by Bottom-Up Approach. Plasma-Assisted Synthesis. Bettge et al. [61] applied plasma-assisted Vapor-Liquid-Soild (VLS) methods [62] and achieved hierarchical $\mathrm{LiMn}_{2} \mathrm{O}_{4}$ thin film electrodes. In this work, an amorphous layer of $\mathrm{Si}$ was first grown on planar stainless steel (SS) substrates using DC magnetron sputtering; then the plasma-assisted VLS was realized to allow the growth of aperiodic $\mathrm{SiO}_{2}$ nanowires. The nanowires were then coated with metallic TiN as current collectors followed by $\mathrm{LiMn}_{2} \mathrm{O}_{4}$ coatings using magnetron sputtering, during which the sample stage was periodically tilted to improve film continuity. It was reported that the films contained the free-standing nanowire morphology and they were well-preserved after cycling. The detailed nanostructure of an individual nanowire is shown in Figure 6(a). It is confirmed that the $\mathrm{LiMn}_{2} \mathrm{O}_{4}$ thin films consist of nanocrystalline grains that are about $5 \mathrm{~nm}$ in size and orient around $45^{\circ}$ with respect to the longitudinal axis of the nanowire due to the shadowing effect introduced by the oblique angle deposition. Such a morphology exhibited the nanoscale roughness with further increased surface areas (about 5 times than planar morphology), thus showing better electrochemical performance compared to planar films. However, as seen in Figure 6(b), the planar film exhibits better cyclability, which may be attributed to (1) the detachment of nanowires or $\mathrm{LiMn}_{2} \mathrm{O}_{4}$ grains due to the interspaced nature of nanowires and grains and (2) the Mn cation dissolution due to increased surface exposure to electrolyte [5]. Despite the undesirable cyclability, the films show an obvious decrease in charge transfer resistance due to the shortened particle dimensions as evidenced by EIS results. This work is a very comprehensive demonstration of a standard design approach especially with the readily available growth of Si nanowires on almost any substrate surfaces. However, silicon is not conductive and requires additional conductive coatings. In order to solve this issue, plasma-assisted synthesis was also applied to achieve carbon-based nanostructures [63].

Mask-Assisted Synthesis. Shaijumon et al. [64] grew Al nanorods directly on $\mathrm{Al}$ foils using pulsed potential electrodeposition with the assistance of anodic aluminum oxide (AAO) membranes [65], and $\mathrm{LiCoO}_{2}$ coating was obtained by thermal decomposition of spray-coated $\mathrm{LiCoO}_{2}$ sol-gel precursors. This method is facile for different cathode systems as $\mathrm{Al}$ is a suitable current collector for positive electrodes; however, the density and distribution of the $\mathrm{Al}$ nanorods heavily depend on the mask quality.

Template-Assisted Synthesis. Liu et al. [24] used engineered tobacco mosaic virus (TMV) as a template for 3D $\mathrm{LiFePO}_{4}$ cathodes with $\mathrm{Ni}$ and $\mathrm{Ti}$ buffer layers as current collectors. TMV is a type of cylindrical particles with a high aspect ratio and can be grafted onto metal surfaces through self-assembly. Yim et al. [66] achieved 3D hemispherestructured $\mathrm{LiSn}_{0.0125} \mathrm{Mn}_{1.975} \mathrm{O}_{4}$ using PS beads as a template. 

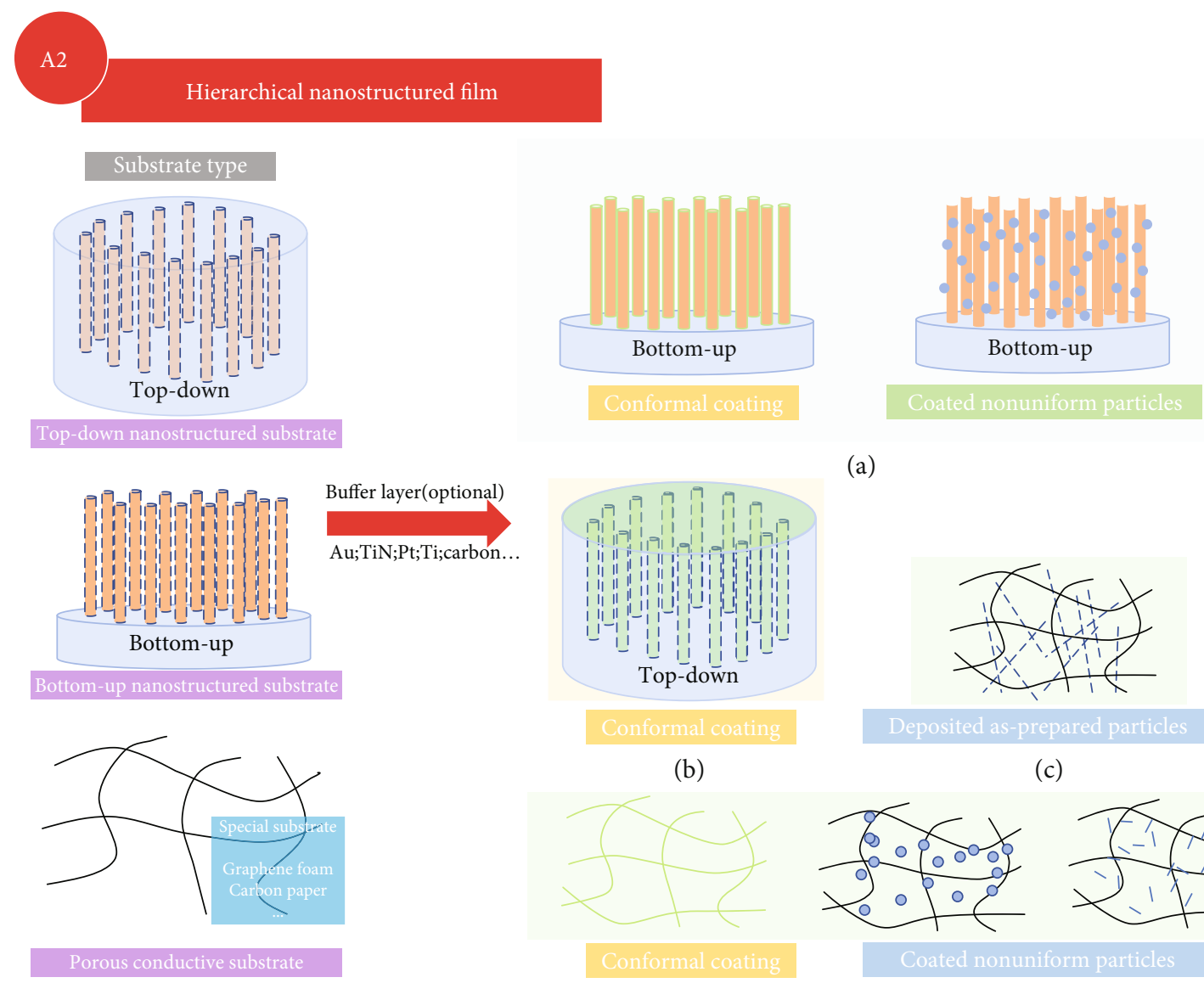

(a)

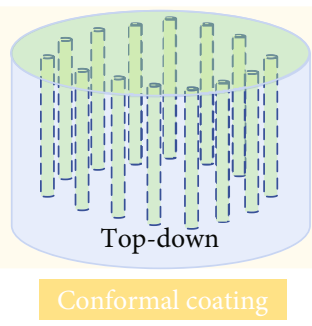

(b)

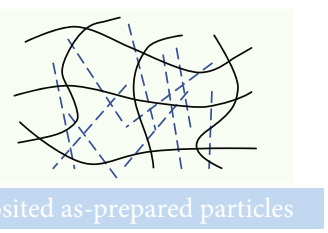

(c)
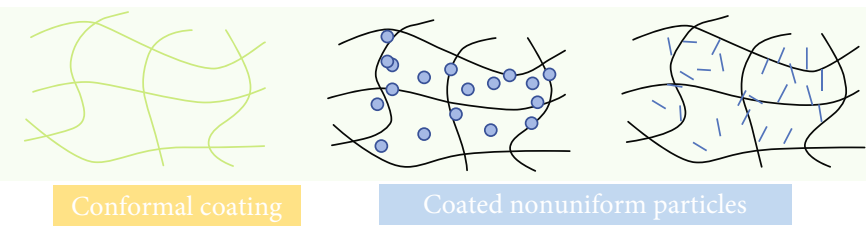

(d)

FIGURE 5: Schematic drawing of different modification approaches on nanostructured substrates: (a) nanostructured substrates obtained by bottom-up methods; (b) nanostructured substrates obtained by top-down methods; (c) direct-deposited particles on porous conductive substrates; (d) coating of cathode materials on porous conductive substrates.

A suspension of polystyrene nanoparticles was spin-coated on $\mathrm{SiO}_{2} / \mathrm{Si}$ substrates, which were then coated with $\mathrm{Ti}$ and Pt coatings, and lastly, $\mathrm{LiSn}_{0.0125} \mathrm{Mn}_{1.975} \mathrm{O}_{4}$ was deposited using RF sputtering. The films exhibited an increased specific capacity and rate performance, but slightly decreased capacity retention due to lack of robustness by hemisphere microstructures when compared to planar films. Templateassisted synthesis enjoys advantages regarding versatile film morphologies and material systems. However, similar to the case of the mask-assisted synthesis, the performances are heavily dependent on the templates and should be designed wisely.

(2) Nanostructured Substrates Obtained by Top-Down Approaches. Chemical Etching Method. Mattelaer et al. [67] derived patterned silicon micropillars using a top-down chemical etching technique for 3D vanadium oxide thin film cathodes with TiN and $\mathrm{Pt}$ as current collectors. Both amorphous and crystalline $\mathrm{VO}_{2}$ and $\mathrm{V}_{2} \mathrm{O}_{5}$ thin films were then conformally deposited on substrates using ALD, and their electrochemical performances were both improved compared to planar geometry. Besides, chemical etching can also achieve different surface morphologies [68] with further enhanced electrochemical performance. However, the thick- ness of films is usually not uniform throughout the surfaces due to the shadowing effect [51]. Therefore, techniques that can achieve conformal coatings are essential for excellent electrochemical performance, and ALD is currently the most fitted technique in this direction $[26,69,70]$. Although coating of randomly distributed particles can easily fix this issue, the loading of active materials is greatly reduced [68].

Lithography Method. Gerasopoulos et al. [71] combined top-down and bottom-up methods to achieve $3 \mathrm{D} \quad \mathrm{V}_{2} \mathrm{O}_{5}$ electrodes. First, Au micropillars were grown on silicon substrates using microplating and lithography. Then, a uniform layer of TMV nanorods was coated on Au micropillar surfaces through self-assembly [24]. Next, a uniform layer of Ni was coated on the TMV rods from an electroless plating bath followed by another layer of conformal $\mathrm{V}_{2} \mathrm{O}_{5}$ through ALD. The results were compared between the nanostructured $\mathrm{V}_{2} \mathrm{O}_{5}$ and hierarchical $\mathrm{V}_{2} \mathrm{O}_{5}$, and the latter one has much higher capacity and rate performance due to further increased surface area. This indicates that, by combining multiple thin film modification approaches, the design can enjoy structural versatilities for property design and the increased surface area can further enhance electrochemical performance as well as loading of active materials. 


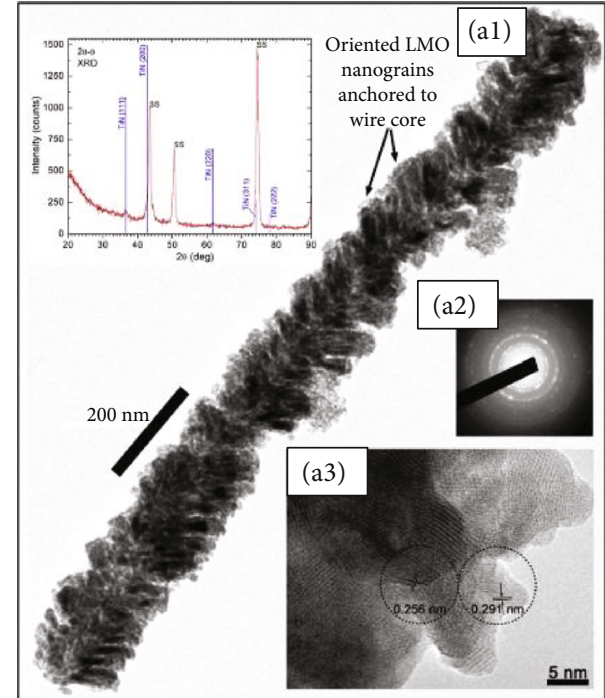

(a)

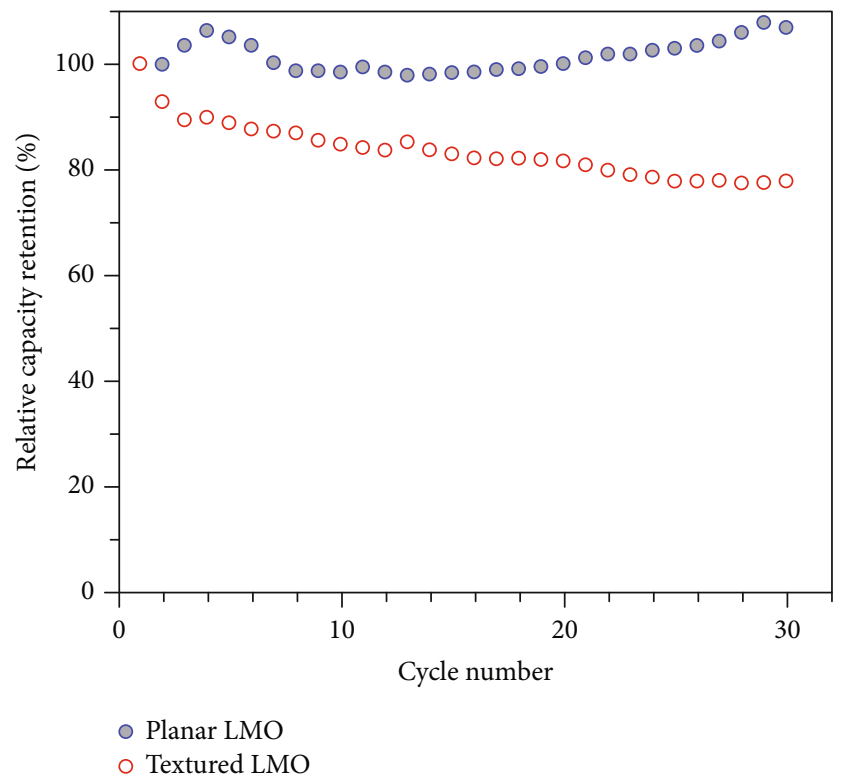

(b)

Figure 6: (a) TEM micrograph of individual nanowire. (b) Cycling performance of nanostructured and planar $\mathrm{LiMn}_{2} \mathrm{O}_{4}$ thin films for 30 cycles [61].

(3) Porous Conductive Substrates with High Surface Area. The above discussion has covered the design of a nanostructured surface on planar substrates and their effects on battery performance. Different from those substrates, some porous conductive substrates, e.g., nickel foams, graphene foams, and carbon papers, can be directly synthesized to build hierarchical 3D electrodes or self-supported flexible electrodes [72]. Among these substrates, the carbon-based substrates are the most studied due to the extremely lightweight and ability to deform.

Deposited Particles. Due to the porous nature of these substrates, as-grown cathode particles can be directly deposited using very simple deposition techniques [73]. Gittleson et al. [74] used spin-spray layer-by-layer deposition of $\mathrm{V}_{2} \mathrm{O}_{5}$ nanowires on porous Celgard separators for transparent energy storage. Seng et al. [75] mixed multiwall carbon nanotubes (MWCNTs) with ultralong $\mathrm{V}_{2} \mathrm{O}_{5}$ nanowires and formed self-supported flexible films using the simple membrane filtration technique. Zhang et al. [76] mixed reduced graphene oxide ( $\mathrm{rGO}$ ) nanosheets with ultralong $\mathrm{V}_{2} \mathrm{O}_{5}$ nanowires under hydrothermal treatment to form flexible films, where the rGO substrates not only increase the electronic conductivity of the films but also suppress the irreversible phase transition of $\mathrm{V}_{2} \mathrm{O}_{5}$ under wide voltage range $(1.0-4.0 \mathrm{~V})$.

Grafted Particles. Despite the simple synthesis procedures, this type of thin film requires large particles to be seated between the empty spaces of the porous substrates, which can lead to unsatisfying cycling performance as the weak material-to-substrate adhesion and limited loading of active materials. Therefore, particles can be grafted onto sub- strate surface through coating techniques to avoid this issue. Sathiya et al. [77] functionalized carbon nanotubes (CNTs) with concentrated nitric acid to introduce function groups and grafted $\mathrm{V}_{2} \mathrm{O}_{5}$ onto the surface through chemical reactions between function groups. The obtained films have a loading of $2 \mathrm{mg} \mathrm{cm}^{-2}$ and show 5\% capacity drop for 25 cycles tested at $0.5 \mathrm{C}$ between $1.5 \mathrm{~V}$ and $4.0 \mathrm{~V}$. Chen et al. [78] synthesized MWCNT sponges using chemical vapor deposition, and $\mathrm{V}_{2} \mathrm{O}_{5}$ was coated as a conformal amorphous layer by ALD. It shows about 7.5\% capacity drop for 25 cycles at $0.2 \mathrm{C}$ but with much higher specific capacity than Sathitya et al.'s report [77]. This work largely improved the mass loading of active materials with the high density CNTs in the sponge, and the core-shell morphology can also overcome the issue of low electrical conductivity and mechanical strength of amorphous $\mathrm{V}_{2} \mathrm{O}_{5}$ [79]. Brown et al. [80] used scalable one-step pulsed electrodeposition technique and grew amorphous $\mathrm{V}_{2} \mathrm{O}_{5}$ on carbon nanofiber membranes (CNFs), which also demonstrated improved electrochemical performance [75].

Other cathode material systems were also explored. Chen et al. [81] grew a layer of densely anchored $\mathrm{VO}_{2}$ nanoflakes on carbon cloth substrates with hydrothermal technique, which gives an initial capacity of $289 \mathrm{mAhg}^{-1}$ at $0.2 \mathrm{C}$ and $126 \mathrm{mAh} \mathrm{g}^{-1}$ at $20 \mathrm{C}$. $\mathrm{LiFePO}_{4}$ nanoparticles were coated on graphene foams (GFs) by Li et al. [82] using a hydrothermal method, providing $164 \mathrm{mAh}^{-1}$ at $0.2 \mathrm{C}$ and $114 \mathrm{mAh} \mathrm{g}^{-1}$ at $50 \mathrm{C}$. The work further demonstrated flexible all-solid-state battery application with good electrochemical performance under repeated mechanical deformation. Besides, $\mathrm{LiFePO}_{4}$ nanosheets/GFs cathodes synthesized by 

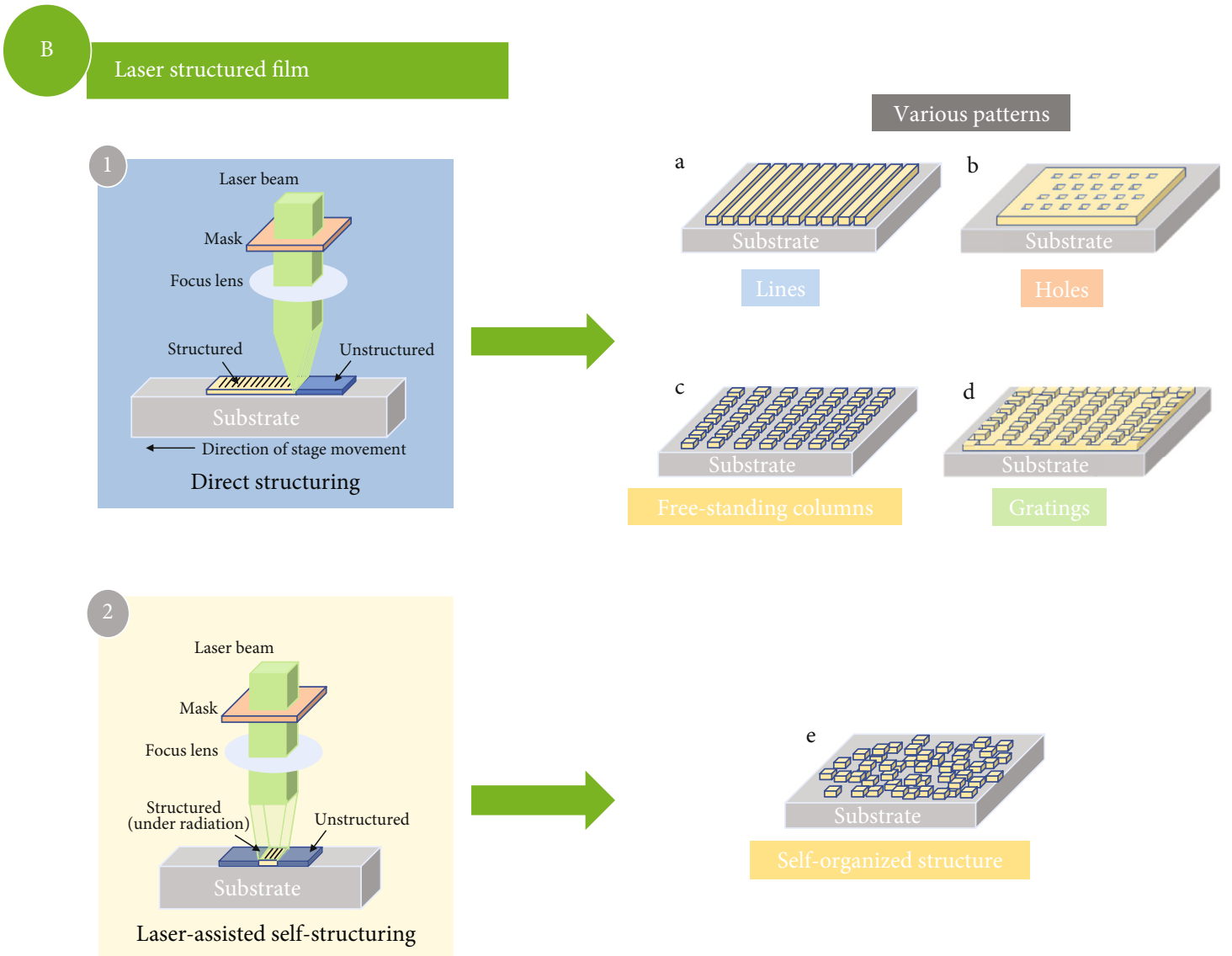

FIGURE 7: Schematic drawing of thin film modification approaches that as-deposited thin film electrodes are nanostructured using laser technique.

the same hydrothermal method show slightly better rate performance than $\mathrm{LiFePO}_{4}$ nanoparticles/GFs, which is expected as the hierarchical nanosheet structure has higher surface areas [83].

In conclusion, film deposition on nanostructured substrates (hierarchical nanostructured films) is a more advanced modification approach for thin film cathodes when compared to only nanostructured films. Particle-coated nanostructured substrates can have more designable variables such as particle morphologies, particle sizes, particle densities, and particle distribution, which on the other hand require more careful control of synthesis parameters. As to conformal coating, the critical issue comes to whether a uniform layer of coating can be achieved, most of which is accomplished by atomic layer deposition or other wet chemicalbased methods [70, 84-86].

3.1.3. Laser-Structured Thin Film Cathodes (a Top-Down Method). The above sections introduced a series of modification approaches involving various thin film techniques such as wet chemistry, vapor deposition, and catalytical growth. Though the abovementioned approaches grant high tunability, desirable structures normally require a complicated synthesis route and postannealing is often time-consuming. Therefore, these advanced 3D electrodes are not costeffective enough to be industrialized at this stage, not to mention that most of the work introduced above involves mainly model cathode materials, indicating its early stage development.

Compared to the above methods, laser-based cathode processing technique is a relatively new modification approach that can achieve designable 3D nanostructures on electrodes and can accomplish an annealing process on a large scale and short time [27]. This approach can also be classified as the top-down method as it is a post treatment and requires as-prepared electrodes. The basic operating principle to realize 3D electrode using laser processing techniques can be classified into two types, which are shown in Figure 7: (1) Direct structuring: a beam of laser is focused on the film surface and the stage will move in a programmable fashion. Different morphologies can be obtained by different combinations of laser mode (pulsed or continuous) and stage movement (direction and speed). (2) Laser-assisted self-structuring: laser beam is shown on the film surfaces, and the active materials will be ablated followed by subsequent redeposition on the film surface to form a structured morphology.

(1) Direct Laser Structuring. Layered-Type Cathode Systems. Most of the current works have been focused on direct structuring due to its programmable characteristics. Kohler et al. [87] used excimer source laser on RF magnetron-sputtered $\mathrm{LiCoO}_{2}$ thin films and obtained two different conical surfaces 

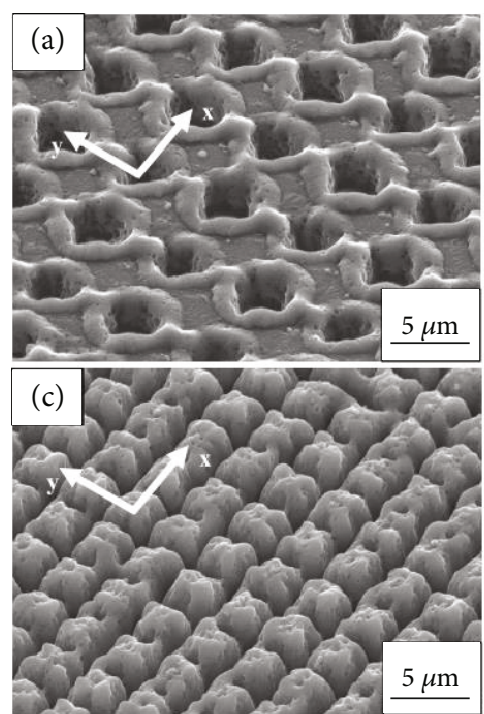

Dis-/charging rate $\mathrm{C} / 2$, voltage $3.0-4.3 \mathrm{~V}$
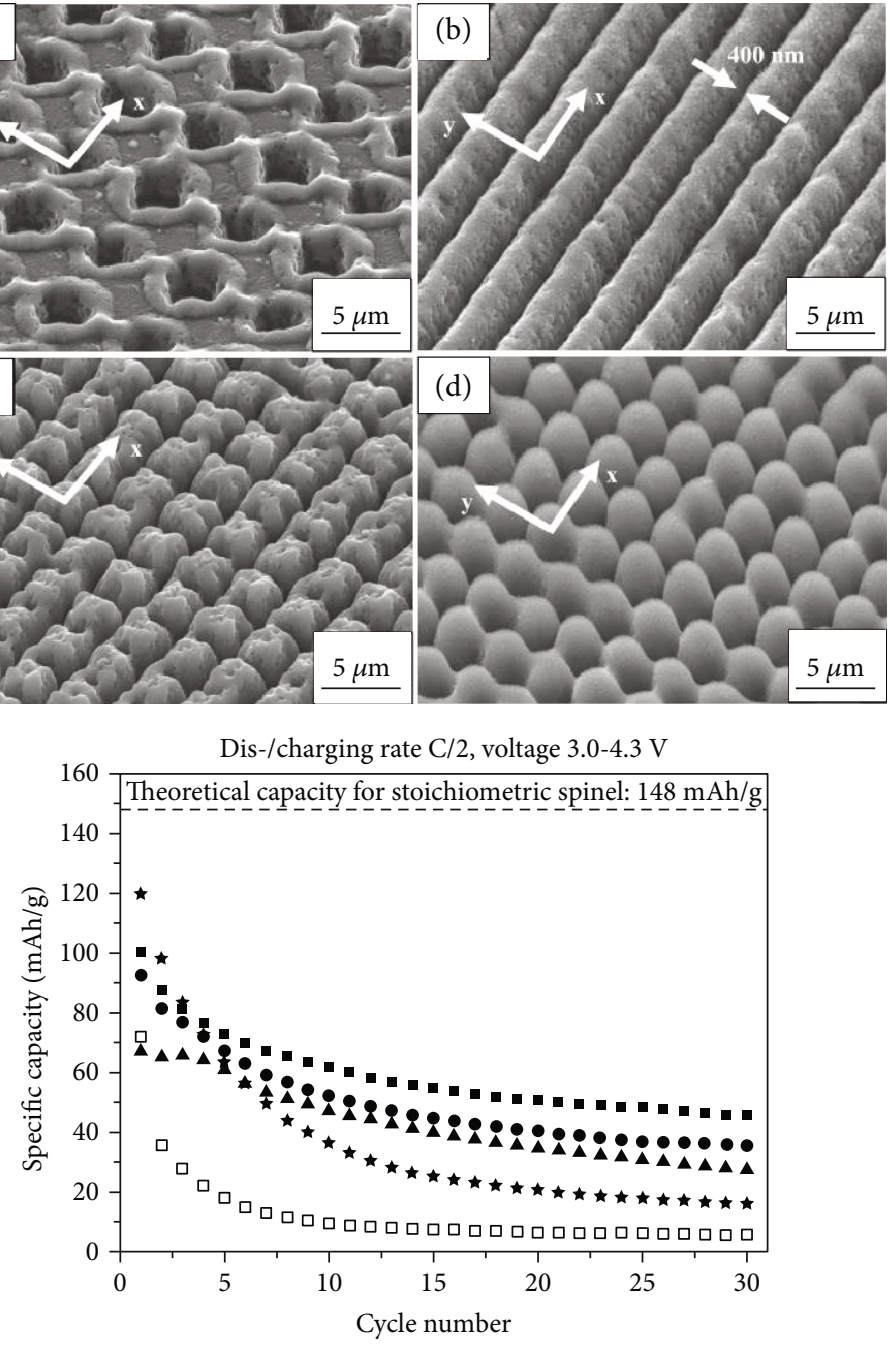

(d)

- Pattern (b), laser-annealed, $\theta=31^{\circ}$

- Pattern (d), laser-annealed, $\theta=24^{\circ}$

- Pattern (a), laser-annealed, $\theta=20^{\circ}$

$\star$ Pattern (c), laser-annealed, $\theta=33^{\circ}$

$\square$ Unstructured, laser-annealed, $\theta=58^{\circ}$

(e)

FIgURE 8: SEM micrographs with different patterns of (a) holes, (b) line, (c) grating, and (d) free-standing surface structures. (e) Cycling performance of $\mathrm{LiMn}_{2} \mathrm{O}_{4}$ thin films with different surface morphologies for 30 cycles at $0.5 \mathrm{C}$ [88].

by changing laser operation modes. The surface structures show 5 to 10 times larger surface area than the as-deposited films. Laser annealing can be performed for only $13.2 \mathrm{~s}$ in ambient air at $700^{\circ} \mathrm{C}$ to obtain HT-LCO phase with improved crystallinity and increased grain size. Laser sources with different wavelengths are affected differently on electrochemical performance as different ablation rates result in different cone heights. This work demonstrated that the surface area can be largely increased by laser structuring, and microstructures as well as electrochemical performance can be tuned by laser operation parameters.

Spinel-Type Cathode Systems. Different film morphologies obtained through direct laser structuring were studied and compared. Pröll et al. [88] used $\mathrm{LiMn}_{2} \mathrm{O}_{4}$ thin film cathodes on stainless steel obtained by RF magnetron sputtering. The wettability of electrolyte and electrochemical performance between different surface morphologies were compared. The four different types of surface morphologies are shown in Figures 8(a)-8(d), and all the nanostructured surfaces show increased wettability with electrolyte. The cycling performance can be seen in Figure 8(e), and the grating structure (Figure 8(d)) shows the highest initial capacity of $120 \mathrm{mAh} \mathrm{g}^{-1}$ at $0.5 \mathrm{C}$ but decays to only $20 \mathrm{mAhg}^{-1}$ at the $30^{\text {th }}$ cycle. The line structure (Figure 8(b)) shows the best cycling performance while not the highest capacity, which is possibly due to the stable structure but smaller surface area when compared to the 
grating structure. Despite the improved electrochemical performance, the authors claim the laser-processed film contains a $30 \%$ loss of active materials due to the laser ablation, which could be a significant issue to active materials loading.

Pröll et al. [89] further optimized processing parameters for laser structuring and annealing, which lowered the active material loss to below $0.13 \%$. However, this study shows different results from the previous report. The free-standing morphology in this study has better rate performance and cyclability compared to line structure, while the two have similar initial capacity. It was explored that the combination of laser structuring as well as laser annealing produced a hierarchical nanoscale and microscale structures which was not discussed in the previous report [88]. The postmortem analysis shows that the line structure exhibits film delamination and cracking, causing bad cycling performance. Furthermore, this result seems to be contradictory to their previous report as well [88]. Further efforts are needed in this area to reach consensus in the field.

(2) Laser-Assisted Self-Structuring. The obvious difference of laser-assisted self-structuring from the direct laser structuring is its free redeposition of the ablated materials on top of the pristine surface structures. Kohler et al. studied electrochemical performance of self-organized $\mathrm{LiCoO}_{2}$ thin film and formation mechanism of conical surfaces [90]. The film demonstrated a similar conical structure with slightly higher randomness compared to directly structured surface and an increase in electrochemical performance as well as cycling stability. Further, as stated above, the formation of such conical structures was proved to consist of different domains with different chemical compositions, thicknesses, and crystallinities, which are related to in situ grain growth from laser radiation and ex situ grain growth from redeposition of ablated particles. By applying the same principle, Hudaya et al. [91] successfully obtained 3D HT-LCO with largely enhanced rate capability.

In short, laser structuring can be a scalable and costeffective process, and the nanostructures can be tuned by different laser sources (excimer lasers, ns fiber lasers, and fs-lasers) and operation details [92]. However, not much work is performed in the thin film electrode field despite the fact that there is an obvious need in the thin film cathode field to achieve scalable capability.

3.2. Nanocomposite Design (Multiple Phases). The above sections have summarized the improvement of electrochemical performance of single phase thin film cathodes via nanostructure designs, with a basic principle, i.e., to design nanostructures with high surface areas that are mechanically stable. However, such designs can have certain inevitable issues; for example, the highly reactive surface states can favor undesirable side reactions at the electrode-electrolyte interfaces $[47,64,77,93]$. Besides, the nanostructured materials can still experience intrinsic property issues such as low conductivity and bad chemical stability due to the limitations of selected active materials. Therefore, the concept of nano- composite can be introduced to overcome these issues by introducing a second phase (or more) that is high in conductivity or chemical stability [94]. This is an important modification approach as it provides flexible nanostructured design approaches.

\subsubsection{Surface Coating Nanocomposite (a Bottom-Up Method)}

(1) Surface Coating on Planar Thin Film Cathodes. Nanocomposite modification types can be simply classified into two groups, i.e., introducing the second phase on top of the matrix phase, that is, surface coating. The schematic drawing in Figure 9 of different surface coating modification types can be divided into (1) surface coating on planar films and (2) surface coating on nanostructured films.

A Physical Protection Layer. Due to the well-known transition metal dissolution and electrolyte oxidation issues of $\mathrm{LiMn}_{2} \mathrm{O}_{4}[7,95]$, this material usually requires surface coatings as physical protective layers [96]. Mattelaer et al. [18] studied the effect of ultrathin amorphous coating of $\mathrm{Al}_{2} \mathrm{O}_{3}$ and $\mathrm{TiO}_{2}$ by $\mathrm{ALD}$ on $\mathrm{Pt} / \mathrm{TiN} / \mathrm{SiO}_{2} / \mathrm{Si}$ substrates. Upon overcharging $(>4.4 \mathrm{~V})$ at a low cycle rate $(0.5 \mathrm{C})$, both $\mathrm{Al}_{2} \mathrm{O}_{3}$ and $\mathrm{TiO}_{2}$ are effective in suppressing electrolyte oxidation, while $\mathrm{TiO}_{2}$ has slightly better suppression but also needs to go through an activation process before it can act as a protective layer. However, the rate performance of $\mathrm{Al}_{2} \mathrm{O}_{3}$-coated $\mathrm{LiMn}_{2} \mathrm{O}_{4}$ deteriorates very fast with increasing $\mathrm{C}$-rate, even worse than uncoated $\mathrm{LiMn}_{2} \mathrm{O}_{4}$, whereas $\mathrm{TiO}_{2}$-coated $\mathrm{LiMn}_{2} \mathrm{O}_{4}$ shows an improved rate capability than uncoated $\mathrm{LiMn}_{2} \mathrm{O}_{4}$. This behavior is also observed morphologically, where the surface of cycled $\mathrm{Al}_{2} \mathrm{O}_{3}$-coated $\mathrm{LiMn}_{2} \mathrm{O}_{4}$ roughens more dramatically than that of $\mathrm{TiO}_{2}$-coated $\mathrm{LiMn}_{2} \mathrm{O}_{4}$, which is because the dielectric $\mathrm{Al}_{2} \mathrm{O}_{3}$ coating only defers the SEI formation but $\mathrm{TiO}_{2}$ suppresses the SEI formation as well as contributing to lithium ion conductivity. In the meantime, Teranishi et al. [97] obtained similar yet more comprehensive conclusions using $\mathrm{LiCoO}_{2}$ electrodes with dielectric $\mathrm{BaTiO}_{3}$ (BTO) coating. Fully covered planar BTO coating and dot BTO partially coated on LCO electrodes were compared, where the planar BTO shows similar results with Mattelaer case [18], but the dot BTO coating shows highly enhanced rate performance, which is explained by Teranishi et al. that the BTO-LCO-electrolyte triple junction generates negative charges by the intensified electric dipole moment at the triple junction, which attracts $\mathrm{Li}^{+}$ions. This work makes a great demonstration on how thin film systems are helpful in analyzing working mechanisms of complicated nanostructured/nanocomposite electrodes without hindering effects from binders or conductive additives.

Besides electrochemically inactive coatings, researchers also applied solid-state electrolyte materials directly as coatings, such as LiPON [98] and $\mathrm{Li}_{3} \mathrm{PO}_{4}$ [99], to improve the electrochemical performance of thin film cathodes.

(2) Surface Coating on Nanostructured Thin Film Cathodes. A Better Conductive Medium. Surface coating techniques are usually applied together with 3D nanostructured electrodes for further improvement in performance as advanced 


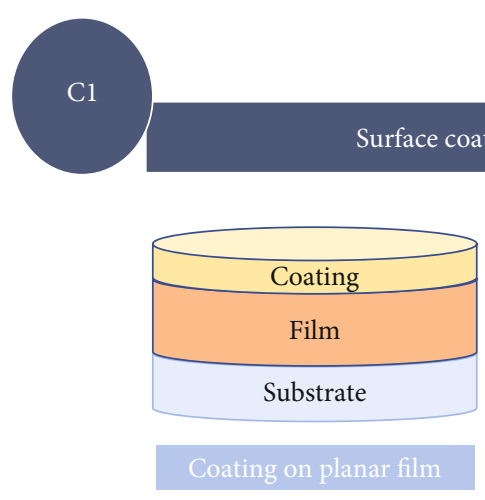

(a)

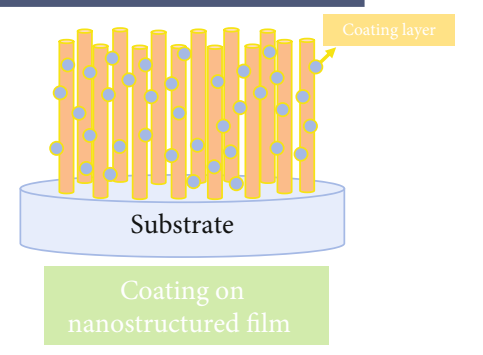

(b)

FIGURE 9: Schematic drawing of thin film modification approach of surface coating on (a) planar or (b) nanostructured thin film electrodes.

electrodes. Olivine $\mathrm{LiFePO}_{4}$ cathodes are known for sluggish kinetics due to the one-dimensional lithium conduction paths and low electrical conductivity of the crystal structure [4]; surface coatings are commonly applied as better electron/ion-conducting media [9, 100]. Carbon coating was applied to tobacco mosaic virus (TMV) template-assisted $\mathrm{LiFePO}_{4}$ nanoforest with $\mathrm{Ti}$ and $\mathrm{Ni}$ as current collectors [24]. C@ $\mathrm{LiFePO}_{4}$ nanoforest cathode shows much better rate performance and cycling stability with nearly $100 \%$ columbic efficiency and pertained morphology after 450 cycles. Similar structures can also be achieved through other synthesis approaches such as laser structuring on carbon-coated planar films [91] or simple PVD technique using composite targets [101].

Instead of the most commonly applied carbon coatings [11], N-doped carbon (N-C) coating can be used as an advanced coating material because $\mathrm{N}$ element was proven to be able to promote electron transfer and lower the energy barrier of lithium penetration in LIB applications [102-104]. A continuous layer of cross-linked N-C@LiFePO $\mathrm{N}_{4}$ particles with nanopores was uniformly decorated on the carbon cloth surface by Pan et al. [105], which improves the gravimetric capacity, rate performance, cycling performance with decreased polarization, and charge transfer resistance when compared to $\mathrm{LiFePO}_{4} / \mathrm{C}$ slurry electrode.

Similar to $\mathrm{LiFePO}_{4}, \mathrm{VO}_{2}$ also experiences low electrical conductivity. $\mathrm{N}-\mathrm{C}$ coating was deposited on $\mathrm{VO}_{2}$ nanoflakes by Chen et al. [81] As shown in Figure 10(a), the $\mathrm{VO}_{2}$ nanoflakes were first anchored on carbon cloth through hydrothermal synthesis, and the $\mathrm{N}-\mathrm{C}$ coating about $3 \mathrm{~nm}$ in thickness was subsequently coated by self-polymerization. The electrochemical performance comparison is shown in Figures 10(b)-10(f). Figure 10(b) shows that N-C@VO has better electrochemical reactivity and smaller polarization due to a better conductive network of N-C coating, which is also confirmed by the EIS results in Figure 10(c). The charge-discharge profile in Figure 10(d) of N-C@VO 2 and $\mathrm{VO}_{2}$ at $0.2 \mathrm{C}$ shows that $\mathrm{N}-\mathrm{C} @ \mathrm{VO}_{2}$ has higher discharge capacity of $325 \mathrm{mAhg}^{-1}$ at $0.2 \mathrm{C}$, lower charge plateau, and higher discharge plateau, as shown in the rate test results in
Figure 10(e). Furthermore, N-C@VO 2 showed good cycling performance with about $9.4 \times 10^{-3} \%$ capacity loss per cycle at $1 \mathrm{C}$ for 500 cycles.

Different from carbon-based coatings, Xia et al. [106] explored hydrogen molybdenum bronze (HMB), an n-type semiconductor with both high electrical conductivity $\left(10^{3}-10^{5} \mathrm{~S} \mathrm{~m}^{-1}\right)$ and ionic conductivity $\left(10^{-3}-10^{-2} \mathrm{~S} \mathrm{~m}^{-1}\right)$, as coating material to improve film kinetics. $\mathrm{VO}_{2}$ nanoflake arrays were obtained on graphene foams (GFs) using hydrothermal synthesis, and a layer of $15 \mathrm{~nm}$ thick HMB shell was coated on the nanoflakes, which largely improves the capacity and rate performance compared to similar $\mathrm{VO}_{2}$ nanoflakes on carbon cloth mentioned above [81]. It exhibits a gravimetric capacity of $415 \mathrm{mAhg}^{-1}$ at $0.2 \mathrm{C}$ and $219 \mathrm{mAhg}^{-1}$ at $30 \mathrm{C}$ with excellent cycling performance at very high rates (about $9.1 \times 10^{-3} \%$ capacity loss per cycle at $30 \mathrm{C}$ for 500 cycles).

A HF Scavenger. Apart from conductive coating functionality, surface coating can also act as $\mathrm{HF}$ scavengers [107] in liquid electrolyte-involved batteries as the inevitable trace amount of moisture in the batteries can react with electrolyte and generate HF to further attack active cathode materials and cause permanent performance decay [108]. It is worth noting that the role of surface coatings is similar to physical protective layers, but in this scenario, the side reaction specifically refers to the HF attack that only occurs in specific battery systems. Liu et al. [109] coated an amorphous layer of $\mathrm{Li}_{3} \mathrm{PO}_{4}$ on amorphous $\mathrm{FePO}_{4}$ by ALD on CNTs. The author observed the increased structural stability of $\mathrm{Li}_{3} \mathrm{PO}_{4}$ coated cathodes as it acts as an $\mathrm{HF}$ scavenger for suppressing the SEI formation. In addition, $\mathrm{Al}_{2} \mathrm{O}_{3}$ was coated on $\mathrm{FeF}_{2}$ with inverse opal $\mathrm{Ni} 3 \mathrm{D}$ scaffold substrates using ALD, which further confirms that combinations between 3D nanostructures and surface coating can maintain good kinetics and suppress side reactions caused by large surface areas [110].

The surface coating approach is an effective method to modify thin film cathodes, and it can be combined with nanostructured cathodes to further improve the performance. Roughly, the surface coating can act differently such as conductivity promoter $[24,81,105,106]$, protective layer [18], HF scavenger in liquid cells [107-110], or surface 


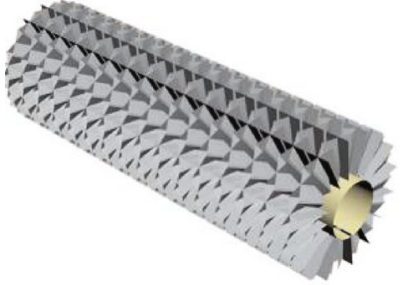

$\mathrm{VO}_{2}$ nanoflakes arrays

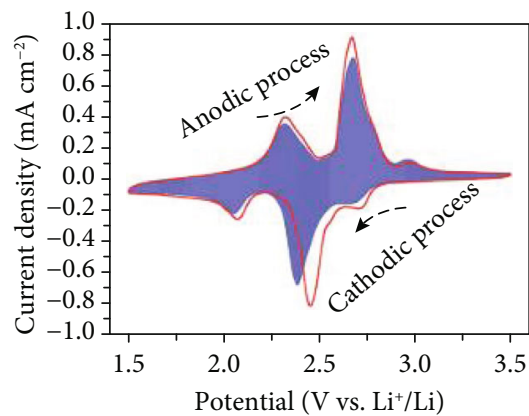

- $\mathrm{VO}$

- N-C@@ $\mathrm{VO}$

(b)

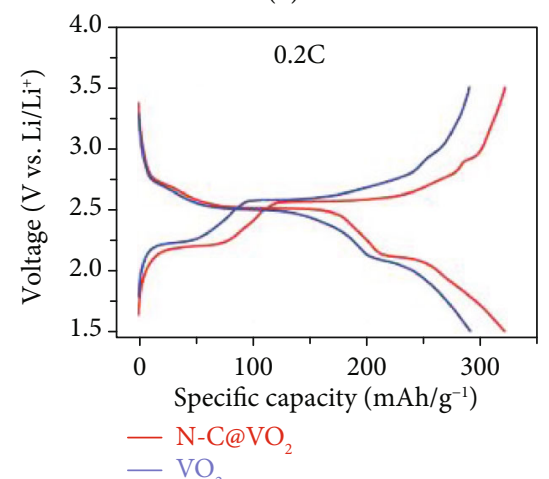

(d)
Polymerization tannealing

$\mathrm{N}-\mathrm{C} @ \mathrm{VO}_{2}$ nanoflakes arrays

(a)
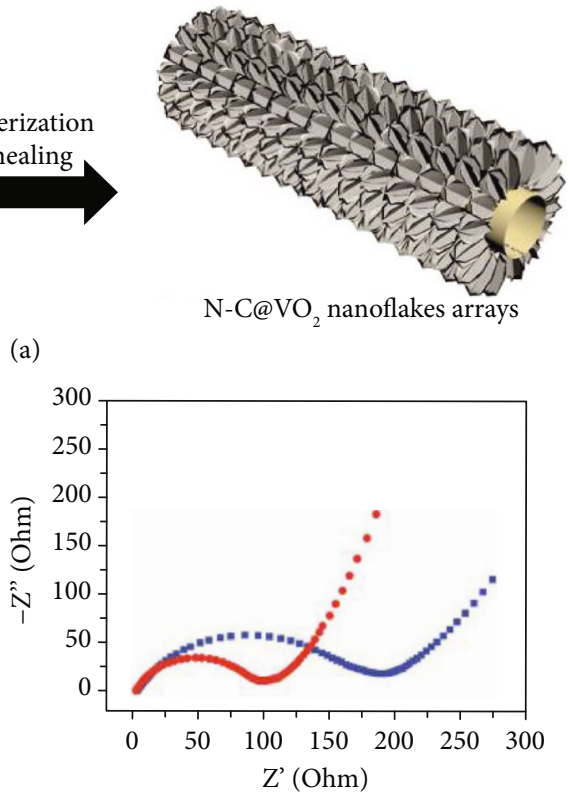

- $\mathrm{VO}$

- N-C@@VO

(c)

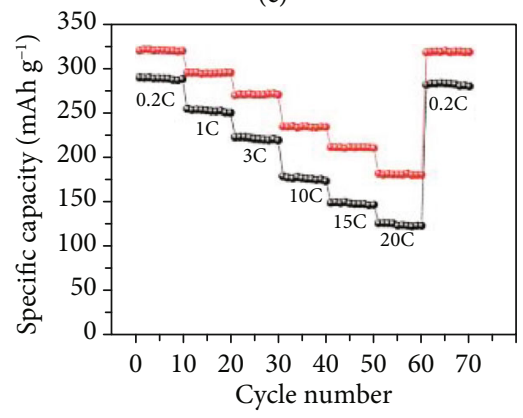

- $\mathrm{VO}_{2}$

$\rightarrow \mathrm{N}-\mathrm{C} @ \mathrm{VO}_{2}$

(e)

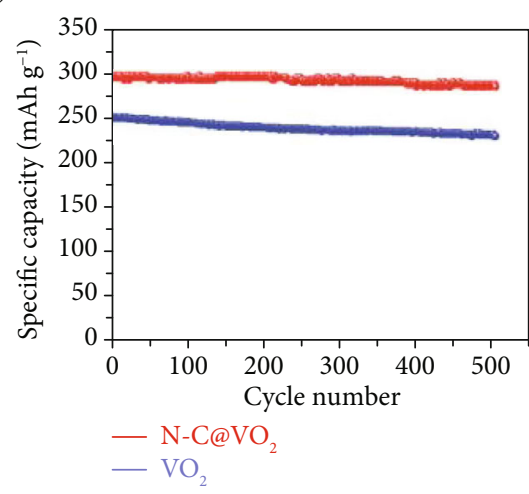

(f)

Figure 10: (a) Schematic illustration of the synthesis procedure of $\mathrm{N}-{\mathrm{C} @ \mathrm{VO}_{2}}_{2}$ nanoflake arrays. (b) Cyclic voltammetry of $\mathrm{VO}_{2}$ nanoflake arrays and $\mathrm{N}-\mathrm{C} @ \mathrm{VO}_{2}$ nanoflake arrays. (c) EIS measurements of $\mathrm{VO}_{2}$ nanoflake arrays and $\mathrm{N}-\mathrm{C} @ \mathrm{VO}_{2}$ nanoflake arrays. (d) Chargedischarge profile of $\mathrm{VO}_{2}$ nanoflake arrays and $\mathrm{N}-\mathrm{C} @ \mathrm{VO}_{2}$ nanoflake arrays at $0.2 \mathrm{C}$. (e) Rate performance of $\mathrm{VO}_{2}$ nanoflake arrays and $\mathrm{N}-\mathrm{C} @ \mathrm{VO}_{2}$ nanoflake arrays at 0.2 C,1 C, 3 C, 10 C, 15 C, and 20 C. (f) Cycling performance of $\mathrm{VO}_{2}$ nanoflake arrays and N-C@VO nanoflake arrays for 500 cycles at $1 \mathrm{C}$ [81]. 


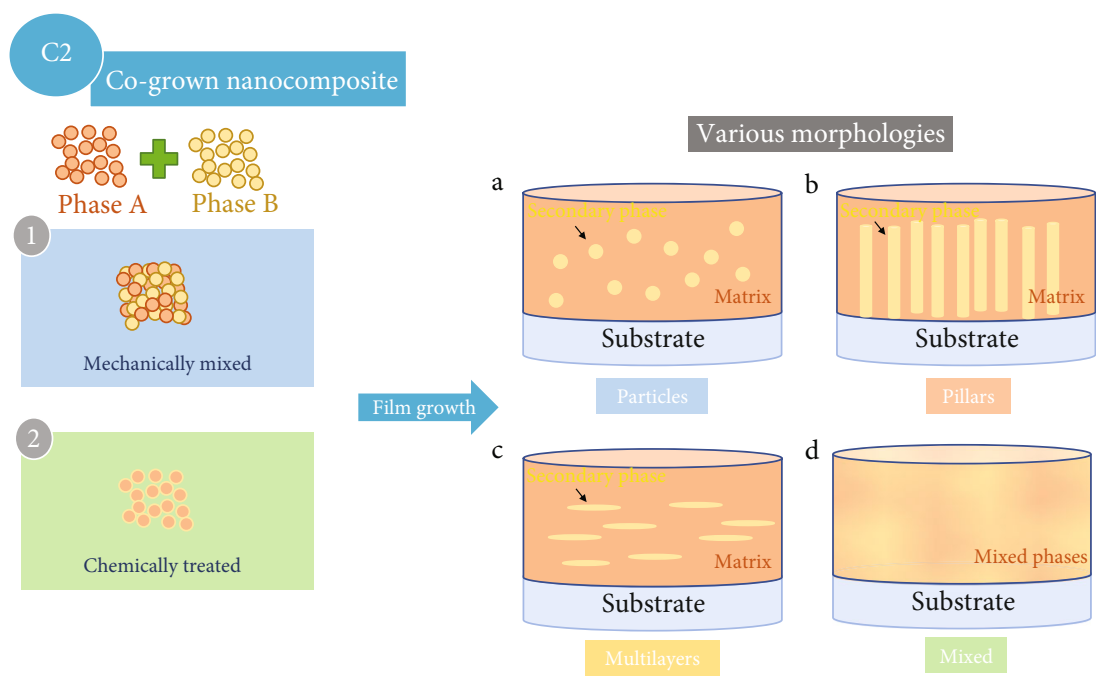

FIGURE 11: Schematic drawing of thin film modification approaches that the secondary phase and matrix phase are codeposited on substrates with tunable secondary phase morphologies. The two phases can be either mechanically mixed or chemically treated.

chemistry modifier (the last example was not introduced above) [111]. Furthermore, the surface coating morphology can be either rough particle coating, core-shell coating, or ultrathin coating with different pros and cons [111].

3.2.2. Cogrown Nanocomposites (a Bottom-Up Method). Apart from surface coatings, nanocomposite approaches can also be designed from the bulk perspective of thin film cathodes. The cogrown nanocomposites can be regarded as a mimic of thick film slurry electrodes with codeposition of two different phases, and the morphology of the secondary phase is tunable in the matrix phase. The most representative modification examples are summarized in Figure 11. In short, the two phases can be mixed either mechanically or chemically, which can then be cogrown on substrates with alterable morphologies such as particles, multilayers, nanopillars, or mixed domains.

(1) Mixed Phase Nanocomposite Thin Film Electrodes. The Carbon Conductive Additives. As it is introduced above, thin film electrodes generally experience slow kinetics, as most cathode materials are oxides with sluggish kinetics, and the attempt of introducing conductive materials into cathode thin films can be traced back to early $2000 \mathrm{~s}$. $\mathrm{LiFePO}_{4}$, as a model system with sluggish kinetics, was studied by Chiu [112]. He mechanically mixed $\mathrm{LiFePO}_{4}$ precursors with carbon sources and made $\mathrm{LiFePO}_{4} / \mathrm{C}$ composite targets. The $\mathrm{LiFePO}_{4} / \mathrm{C}$ composite films were deposited by RF magnetron sputtering on $\mathrm{Si}(100)$ and stainless steel substrates under optimized growth parameters, which show increased capacity and decreased resistance compared to pure $\mathrm{LiFePO}_{4}$. Afterward, Chiu et al. [113] further applied a layer of $\mathrm{Ti}$ buffer and proved it being able to enhance crystallization and grain growth and increase film-to-substrate adhesion. Further, Lu et al. [114] and Zhou et al. [115] explored the effect of carbon amount in the cathode matrix. Despite the different conclusions in detail [58], they arrived at a general trend that the specific capacity will be lowered but the kinetics of the electrodes will be improved with an increase in carbon amount. In detail, Lu et al. used poly(vinyl alcohol) and Zhou et al. applied sucrose pyrolysis as carbon sources. However, Lu et al. stated that $2 \mathrm{wt} . \%$ carbon content is necessary to ensure satisfying electrochemical performance and further increase the carbon amount can cause film shrinkage, delamination [114], and cracking whereas Zhou et al. claimed $23 \mathrm{wt} . \%$ carbon is the optimal amount and higher amount of carbon can block the lithium diffusion [115].

The Metal Conductive Additives. Conductive materials other than carbon were also studied. Lu et al. [116] used Ag as the secondary conductive phase. Different from the mechanically mixed carbon source and $\mathrm{LiFePO}_{4}, \mathrm{Ag}$ was chemically coated on $\mathrm{LiFePO}_{4}$ particles via a colloidal process before being mixed and pressed into a composite target, where the composite film was then deposited on $\mathrm{Pt} / \mathrm{Ti} /$ $\mathrm{SiO}_{2} / \mathrm{Si}$ substrates using $\mathrm{PLD}$. The $\mathrm{LiFePO}_{4} / \mathrm{Ag}$ composite films demonstrate much higher volumetric capacity, better rate performance, and increased cycling stability with a much lower weight percent of $\mathrm{Ag}$ compared to $\mathrm{LiFePO}_{4} / \mathrm{C}$ films. This behavior can be possibly explained by the more uniform mixture between active materials and conductive materials through chemical coating at an atomic level compared to simple mechanical mixing [58]. In addition to $\mathrm{Ag}, \mathrm{Au}$ and mixed metals were also studied for $\mathrm{LiFePO}_{4}$ [117], and the mixed metal can not only increase kinetics but also prevent the active materials from unfavorable side reactions for certain cathode systems [118].

(2) Particle-in-Matrix Nanocomposite Thin Film Electrodes. All the above works lack the discussion from the morphological perspective of the nanocomposites; that is, no direct evidence such as TEM images was presented to confirm how the secondary phase is distributed in the matrix phase, which could lead to inaccurate conclusions. For example, Eftekhari claims that cobalt oxide exists as surface coating on $\mathrm{LiMn}_{2} \mathrm{O}_{4}$ 


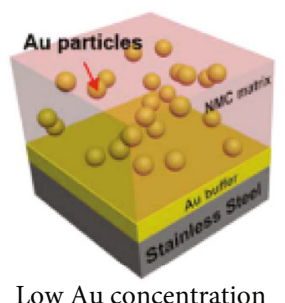

(a)

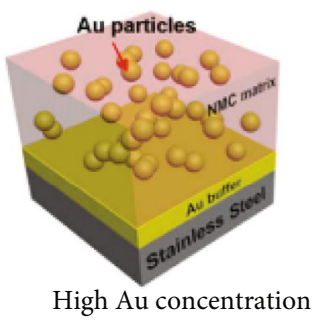

Cross section NMC+Au

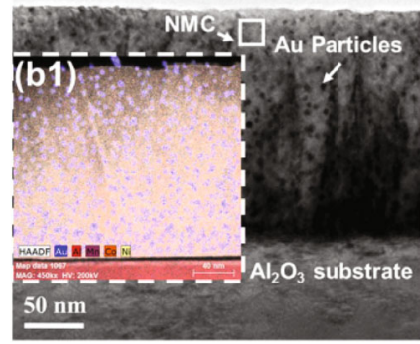

(c)

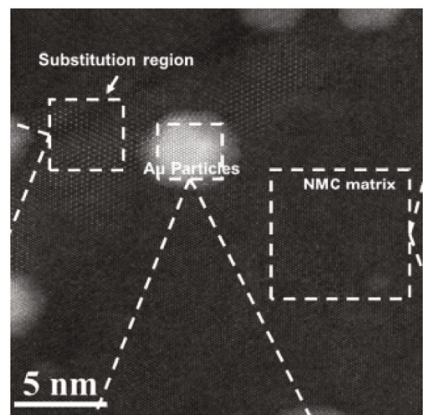

(d)

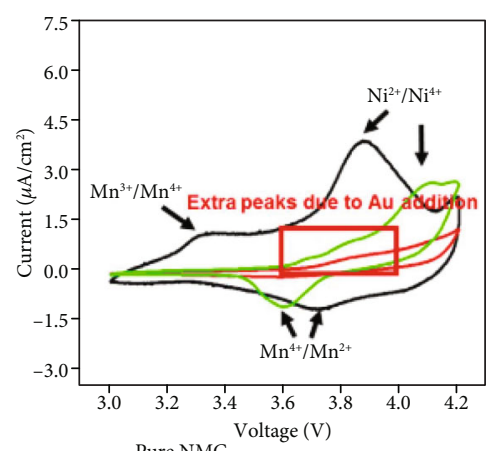
- Pure $\mathrm{NMC}$

(e)

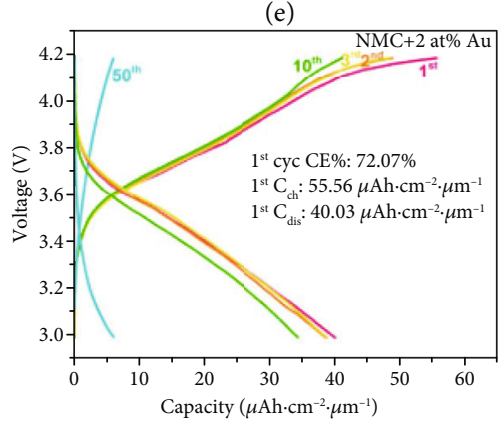

(f)

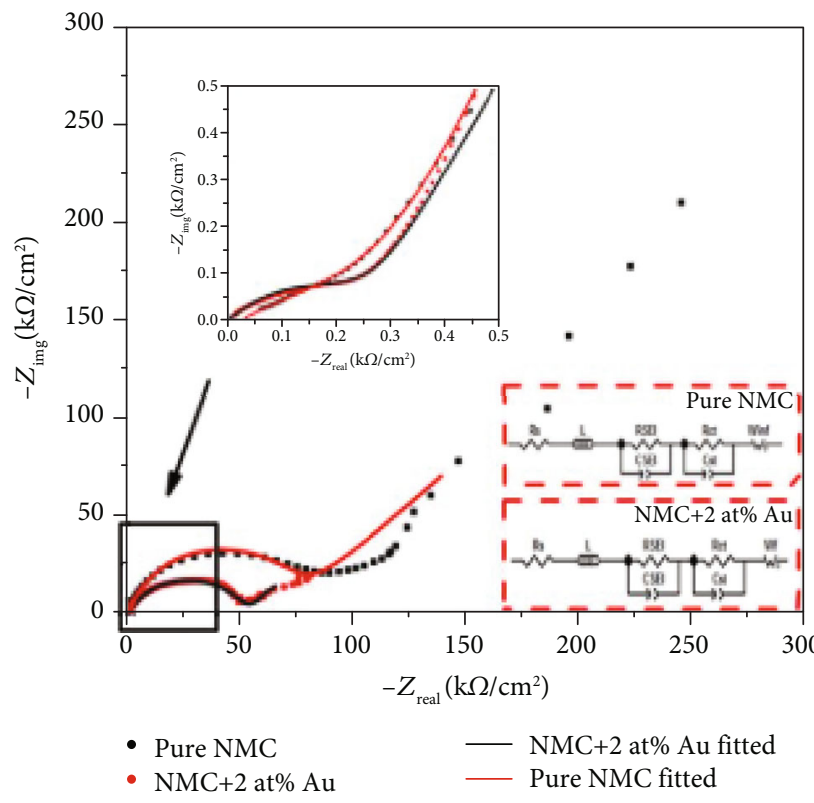

(g)

FIgURE 12: (a) Schematic drawing of NMC-Au nanocomposite with low Au concentration. (b) Schematic drawing of NMC-Au nanocomposite with high Au concentration. (c) Low-mag TEM images of cross-sectional NMC-Au nanocomposite thin film; the inset shows the corresponding EDX mapping. (d) HRSTEM of plan-view NMC-Au nanocomposite thin film. (e) Cyclic voltammetry of pure NMC, NMC-2 at\% Au, and NMC-6 at\% Au. (f) Cycling performance of NMC-2 at\% Au nanocomposite for 50 cycles. (g) EIS results of pure NMC and NMC-2 at\% Au with fitted equivalent circuits plotted [125].

through a mixed-metal codeposition process [118] because the capacity fade was suppressed and surface coating was proved to be effective in this sense [111]. However, this suppression could also be from the change of Mn valence states due to the interdiffusion of cobalt oxide phase with different morphologies [7]. This lacking perspective is critical as it can provide design insights and is helpful in studying working mechanisms. 


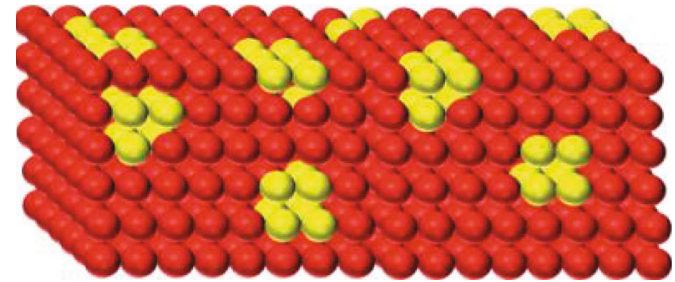

(a)

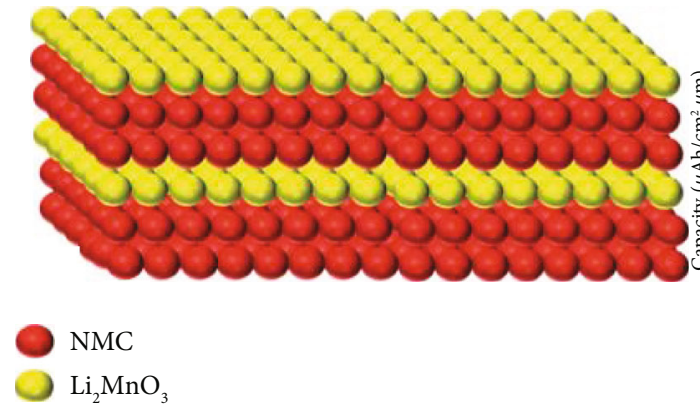

(b)
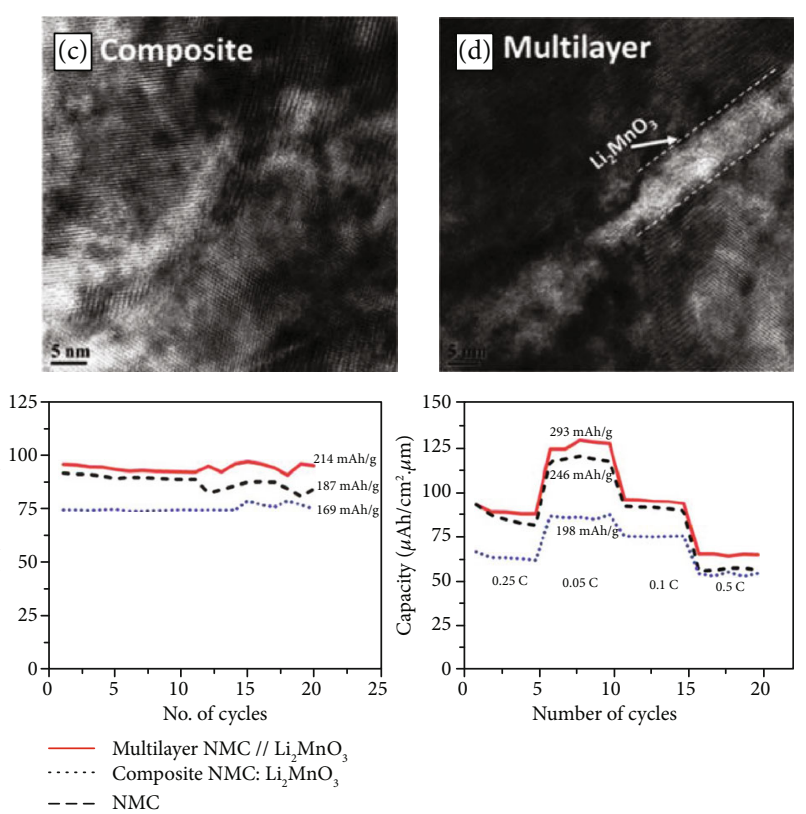

(e)

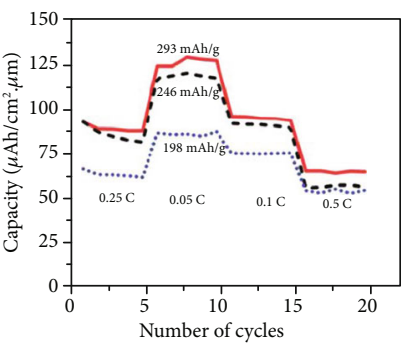

(f)

Figure 13: (a) Schematic drawing of composite $\mathrm{NMC}-\mathrm{Li}_{2} \mathrm{MnO}_{3}$ thin film. (b) Schematic drawing of multilayered $\mathrm{NMC}^{-\mathrm{Li}_{2} \mathrm{MnO}} \mathrm{O}_{3}$ thin film. (c) TEM micrograph showing microstructure of composite $\mathrm{NMC}-\mathrm{Li}_{2} \mathrm{MnO}_{3}$ thin film. (d) TEM micrograph showing microstructure of multilayered NMC- $\mathrm{Li}_{2} \mathrm{MnO}_{3}$ thin film. (e) Cycling performance of composite $\mathrm{NMC}-\mathrm{Li}_{2} \mathrm{MnO}_{3}$, multilayered $\mathrm{NMC}-\mathrm{Li} \mathrm{MnO}_{3}$, and pure NMC for 25 cycles. (f) Rate capability of composite $\mathrm{NMC}-\mathrm{Li}_{2} \mathrm{MnO}_{3}$, multilayered $\mathrm{NMC}-\mathrm{Li}_{2} \mathrm{MnO}_{3}$, and pure NMC. (Reproduced from Ref. [124] with permission from the Royal Society of Chemistry.)

The Metal Conductive Additives. PLD, known as an easy stoichiometry control technique [83, 119-122], combined with careful TEM studies examining the microstructures of thin film cathodes has been proven effective in studying fundamental mechanisms of cathode materials and improving electrochemical performance [37, 123-125]. Inspired by $\mathrm{LiFePO}_{4} / \mathrm{Ag}$ composite example, $\mathrm{LiNi}_{0.5} \mathrm{Mn}_{0.3} \mathrm{Co}_{0.2} \mathrm{O}_{2}(\mathrm{NM}-$

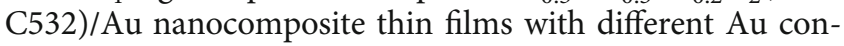
centrations were deposited on Au-buffered stainless steel substrates, as schemed in Figures 12(a) and 12(b) [125]. The films were deposited by applying NMC/Au composite targets with different $\mathrm{Au}$ concentrations. The crosssectional low-mag TEM images in Figure 12(c) confirm the existence of $\mathrm{Au}$ as embedded particles, and the inset EDX mapping confirms the correct composition of the films. Besides, the microstructure can be decided as faceted nanoparticles from the HRSTEM micrograph in Figure 12(d). It is also worth noting that some Au substituted matrix regime can be observed near domain boundaries, indicating the existence of $\mathrm{Au}$ dopant in NMC532. The CV results in Figure 12(e) demonstrate several facts: (1) $\mathrm{Mn}^{3+}$ exists in pure $\mathrm{NMC}$ but not $\mathrm{NMC} / \mathrm{Au}$ composite films; (2) $\mathrm{NMC} / \mathrm{Au}$ composites show extra $\mathrm{Ni}^{2+} / \mathrm{Ni}^{4+}$ peaks; (3) NMC/2 at $\% \mathrm{Au}$ composite film has similar $\mathrm{Ni}^{4+} / \mathrm{Ni}^{2+}$ peak intensity but much lower $\mathrm{Ni}^{2+} / \mathrm{Ni}^{4+}$ peak intensity compared to pure NMC; (4) NMC/6 at\% Au shows almost no intercalation reaction. The above results indicate the Au dopant has changed the chemical environment of $\mathrm{Ni}^{2+}$ ions and increased chemical stability. Furthermore, a moderate amount of $\mathrm{Au}$ addition can improve the electrochemical reversibility, but over-added $\mathrm{Au}$ shows almost no electrochemical performance due to the disruption of the crystal structure. The cycling performance of $\mathrm{NMC} / 2$ at $\%$ Au composite film for 50 cycles is shown in Figure 12(f), which is superior than pure NMC and NMC/6 at\% Au (not shown here). The enhancing mechanism of Au particles can be explained with the EIS results shown in Figure 12(g), where the infinite length Warburg element is used in the equivalent circuit model to fit the data of pure NMC and finite length Warburg is used for $\mathrm{NMC} / 2$ at\% Au composite film, which suggests the Au particles act as local current collectors in the electrode and shortens the lithium/electron diffusion pathways. What is more, the smaller semicircle of $\mathrm{NMC} / 2$ at $\%$ Au means a decreased charge transfer resistance due to introduction of Au particles.

The Property Compensators. The secondary phase can not only enhance conductivity but also act as a structural stabilizer, as a cost reducer, or simply any role to compensate for the downside of matrix materials. Shi et al. [126] designed a very simple composite structure of pure phase $\mathrm{LiV}_{3} \mathrm{O}_{8}$, but with nanocrystalline phases dispersed in an amorphous matrix. Amorphous $\mathrm{LiV}_{3} \mathrm{O}_{8}$ has larger lithium diffusion coefficient, giving higher capacity and rate performance, whereas crystalline $\mathrm{LiV}_{3} \mathrm{O}_{8}$ has better capacity retention. This simple nanocomposite design combined both the advantages of amorphous and crystalline $\mathrm{LiV}_{3} \mathrm{O}_{8}$, and the properties can be further tuned by the ratio and distribution of the two phases. Yu et al. [127] followed a similar design principle and achieved nanocrystalline $\mathrm{Li}_{4} \mathrm{Ti}_{5} \mathrm{O}_{12}(\mathrm{LTO}) / \mathrm{TiO}_{2}(\mathrm{TO})$ nanocomposite. LTO contains a stable structure upon cycling 


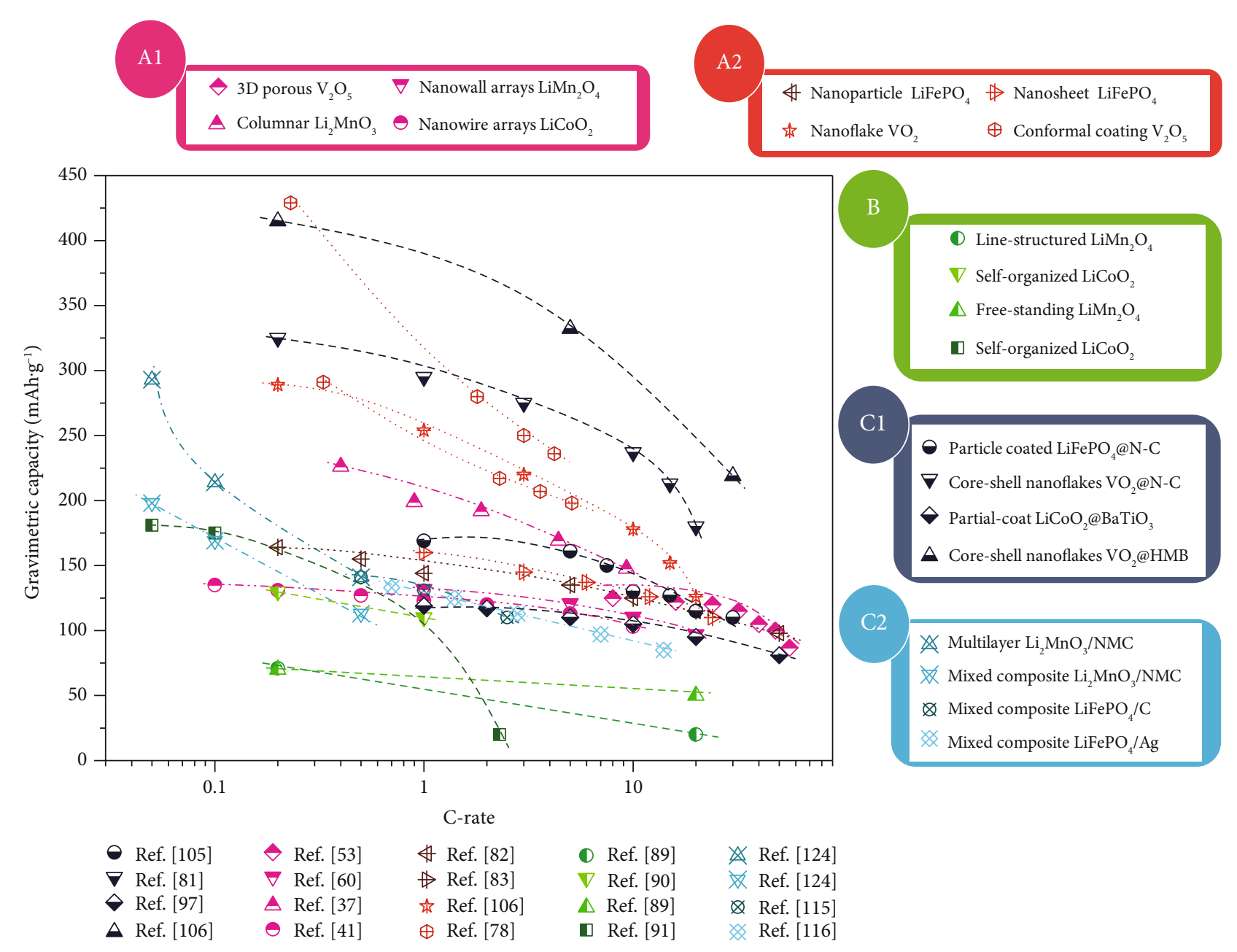

Figure 14: Peukert plot of representative thin film cathode electrodes modified with approaches A1, A2, B, C1, and C2 [37, 41, 53, 60, $78,81-83,89-91,97,105,106,115,116,124]$.

while TO has better rate performance. The nanocrystalline composite provides high density of grain boundaries and electrolyte available channels for high capacity and good cycle stability.

(3) Multilayered Nanocomposite Thin Film Electrodes. The Property Compensators. The composite Li-rich cathode has a very large voltage window, high reversible capacity, and decreased cost due to the introduced secondary structural stabilizing phase $\left(\mathrm{Li}_{2} \mathrm{MnO}_{3}\right)$, but how $\mathrm{Li}_{2} \mathrm{MnO}_{3}$ takes role in the composite remains debating [36]. Jacob et al. studied the performance between traditional Li-rich mixed phase composite cathode and multilayered nanocomposite where the $\mathrm{Li}_{2} \mathrm{MnO}_{3}$ exists in an NMC matrix with multilayer morphology [124], which is schemed in Figures 13(a) and 13(b). The multilayer composite has the isolated nanosized $\mathrm{Li}_{2} \mathrm{MnO}_{3}$ multilayer domains whereas the mixed phase composite has uniformly mixed two materials, as indicated in Figures 13(c) and 13(d), which allows higher capacity and better rate performance (Figure 13(f)) as the lithium diffusion behavior and pathways are more affected by NMC, that is, more conductive. In the meantime, the nanosized domains still stabilize the structure with better cycling performance shown in Figure 13(e). The work demonstrates the tunability of electrochemical performance with different morphologies of the secondary phase, and the additive-free thin films can provide new insight for nanocomposite design [128].

In short, the nanocomposite design is also a promising solution to improve the film kinetics like the single-phase nanostructure design. Additionally, with correct selection of the secondary phase, this method can help compensate for the downside of the nanostructured electrodes such as highly reactive electrode-electrolyte interfaces. However, there is lack of work regarding the morphological study of cogrown nanocomposites, which can provide insights on designing advanced thin film cathode materials.

\section{Conclusions and Outlook}

Thin film batteries are promising for high-power lithium ion batteries as the reduced thickness allows faster lithium diffusion in the electrodes. However conventional 2D planar film geometries could have limited energy loading due to the constraint footprint. Therefore, modification of thin film electrodes is necessary to meet industrial standards. In this 


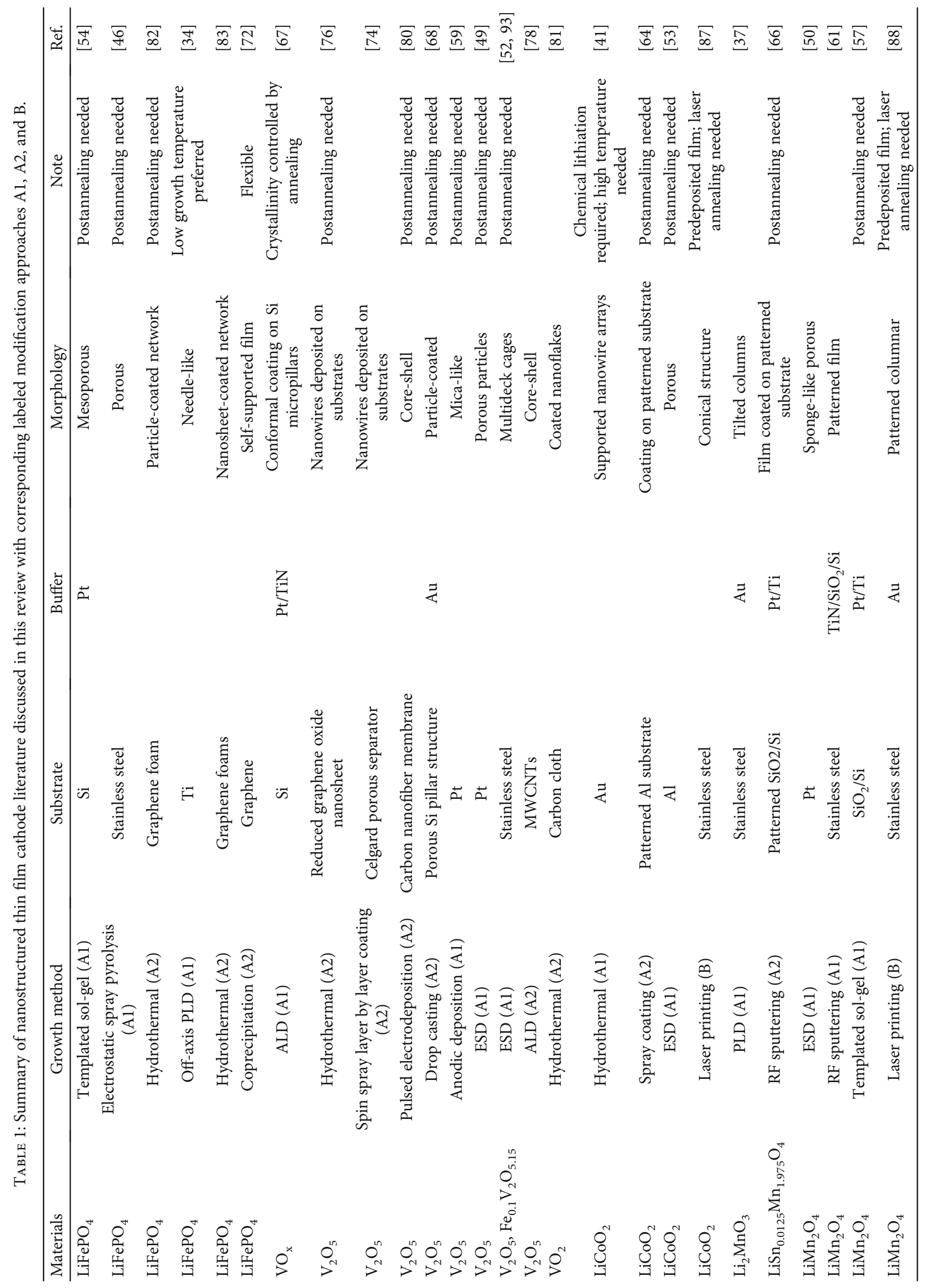




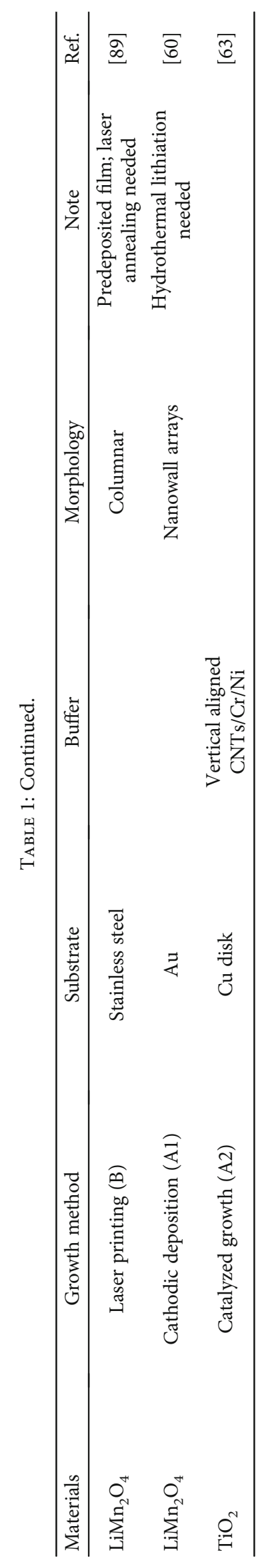




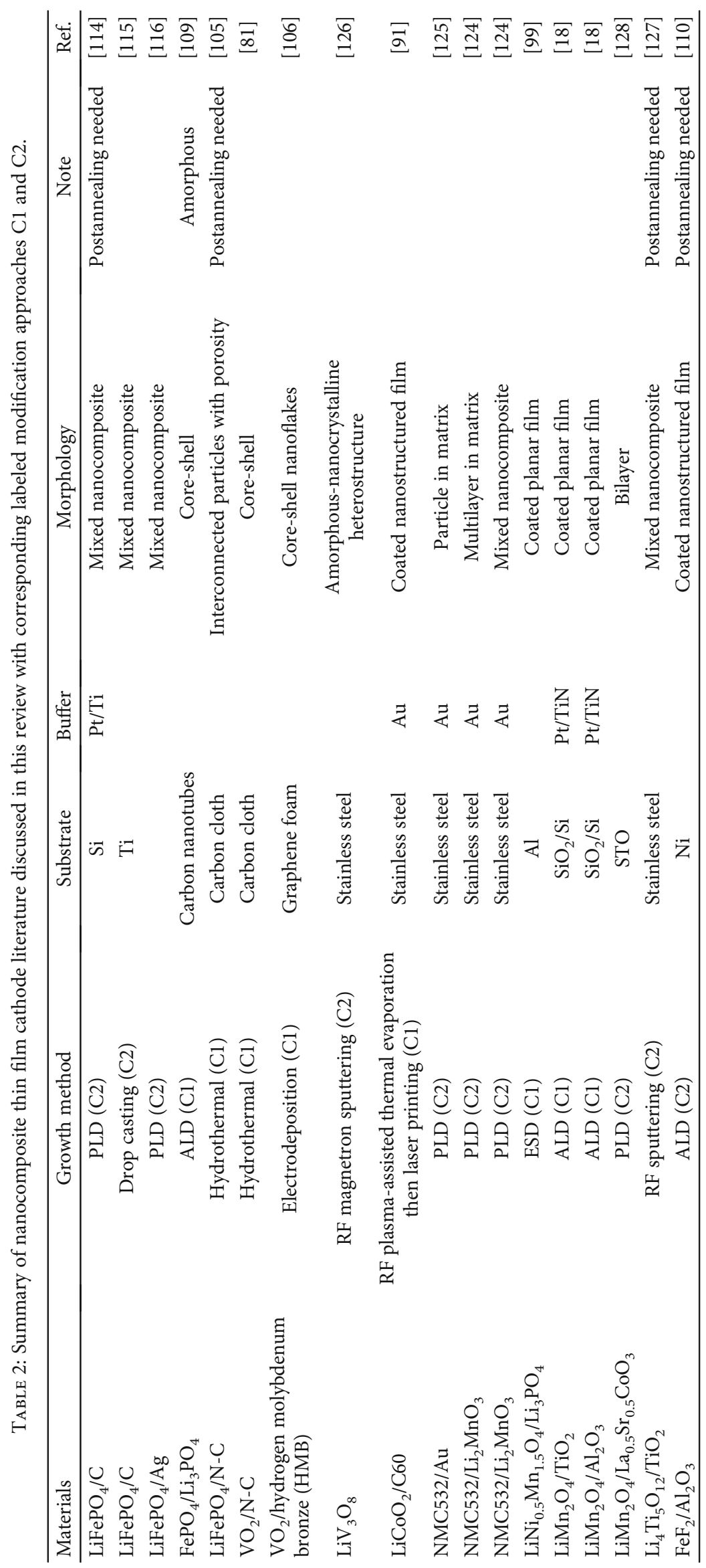


review, we have reviewed representative advancements of thin film cathode electrodes using nanostructure and nanocomposite concepts for advanced lithium ion battery applications. It can be summarized as follows:

(1) Thin film cathode materials can provide satisfying electrochemical performance without binder and conductive additives through either nanostructure or nanocomposite modification techniques

(2) Among all the modification approaches for thin film cathode, nanostructure modification is well explored and studied

(3) The overall design principle of nanostructure modification approaches is to increase a surface-to-volume ratio, which could, however, result in undesirable side reactions. Surface coating technique is a typical solution to prevent side reactions

(4) Among the nanocomposite approaches, the coating technique is currently the most versatile and useful modification technique to prevent side reaction or increase film conductivity, and the technique of cogrowth nanocomposite has been widely utilized to improve the conductivity of thin film cathodes

In addition, several key perspectives have been summarized below:

(1) Among all the techniques to achieve nanostructured thin film cathodes, electrostatic spray deposition (ESD) is a very versatile and simple technique to achieve a film with a high surface-to-volume ratio, which could be an easy choice when growing nanostructured thin film cathode

(2) Substrate choice can be very versatile. Recent focus is on porous carbon-based substrates due to lightweight and high surface area, which could be a promising candidate for thin film cathode development. However, the uniform coating of the cathode is a critical factor to ensure the energy loading density and could be achieved by atomic layer deposition or some solution-based deposition techniques

(3) In terms of nanocomposite design, a conclusive design principle is very much needed. For example, multiple pulsed laser deposition studies demonstrated the effectiveness of tuning the electrochemical performance of thin film cathode through controlling the morphology of the secondary phase in the matrix. A further study on the effect of secondary phase morphology towards the cathode performance is needed

(4) Thin film electrodes have advantages in all-solidstate battery integration. Therefore, advanced thin film electrolyte and thin film anodes using either nanostructure or nanocomposite approach also need to be further studied. In addition, researches should be focused on interfacial interactions between electrolyte, cathode, and anode
We selected the reported data of several representative modified thin film cathode materials modified by approaches A1-C2 (Figure 2) and summarized in the Peukert plot shown in Figure 14, which can provide basic guidance for future research to design advanced thin film cathode electrodes. Furthermore, we have provided the information of the thin film cathode literature about nanostructure modification and nanocomposite modification reported above in Tables 1 and 2, respectively, which summarized the cathode material system, growth method, substrate, buffer layer, and obtained morphologies. All in all, thin film cathode is a critical fundament for advanced lithium ion batteries; however, significant efforts are still required to fulfill a promising thin film cathode field with more effective modification approaches.

\section{Conflicts of Interest}

We declare that we have read research's full conflict of interest policy and have disclosed all declarable relationships therein, if any.

\section{Acknowledgments}

This work is supported by the U.S. Office of Naval Research (ONR, N00014-16-1-2465).

\section{References}

[1] J. M. Tarascon and M. Armand, "Issues and challenges facing rechargeable lithium batteries," Nature, vol. 414, no. 6861, pp. 359-367, 2001.

[2] R. Marom, S. F. Amalraj, N. Leifer, D. Jacob, and D. Aurbach, "A review of advanced and practical lithium battery materials," Journal of Materials Chemistry, vol. 21, no. 27, article 9938, 2011.

[3] M. S. Whittingham, "Lithium batteries and cathode materials," Chemical Reviews, vol. 104, no. 10, pp. 4271-4301, 2004.

[4] A. K. Padhi, K. S. Nanjundaswamy, and J. B. Goodenough, "Phospho-olivines as positive-electrode materials for rechargeable lithium batteries," Journal of the Electrochemical Society, vol. 144, no. 4, pp. 1188-1194, 1997.

[5] T. Aoshima, K. Okahara, C. Kiyohara, and K. Shizuka, "Mechanisms of manganese spinels dissolution and capacity fade at high temperature," Journal of Power Sources, vol. 97-98, pp. 377-380, 2001.

[6] K. Yoon and K. Kim, "Investigations into capacity fading as a result of a Jahn-Teller distortion in $4 \mathrm{~V} \mathrm{LiMn}_{2} \mathrm{O}_{4}$ thin film electrodes," Electrochimica Acta, vol. 49, no. 20, pp. 33273337, 2004.

[7] D. H. Jang, Y. J. Shin, and S. M. Oh, "Dissolution of spinel oxides and capacily losses in $4 \mathrm{~V} \mathrm{Li} / \mathrm{Li}_{x} \mathrm{Mn}_{2} \mathrm{O}_{4}$ cells," Journal of the Electrochemical Society, vol. 143, pp. 2204-2211, 1996.

[8] S. Laubach, S. Laubach, P. C. Schmidt et al., "Changes in the crystal and electronic structure of $\mathrm{LiCoO}_{2}$ and $\mathrm{LiNiO}_{2}$ upon Li intercalation and de-intercalation," Physical Chemistry Chemical Physics, vol. 11, no. 17, pp. 3078-3289, 2009.

[9] J. Chen, C. Hsu, Y. Lin, M. Hsiao, and G. T. Fey, "High-power $\mathrm{LiFePO}_{4}$ cathode materials with a continuous nano carbon network for lithium-ion batteries," Journal of Power Sources, vol. 184, no. 2, pp. 498-502, 2008. 
[10] Y. Wang, Y. Wang, E. Hosono, K. Wang, and H. Zhou, “The design of a LiFePO4/carbon nanocomposite with a core-shell structure and its synthesis by an in situ polymerization restriction method," Angewandte Chemie, International Edition, vol. 47, no. 39, pp. 7461-7465, 2008.

[11] J. Wang and X. Sun, "Understanding and recent development of carbon coating on $\mathrm{LiFePO}_{4}$ cathode materials for lithiumion batteries," Energy \& Environmental Science, vol. 5, no. 1, pp. 5163-5185, 2012.

[12] G. T. Fey, H. Tu, K. Huang, Y. Lin, H. Kao, and S. Chan, "Particle size effects of carbon sources on electrochemical properties of $\mathrm{LiFePO}_{4} / \mathrm{C}$ composites," Journal of Solid State Electrochemistry, vol. 16, no. 5, pp. 1857-1862, 2012.

[13] A. Jiang, X. Wang, M. Gao et al., "Enhancement of electrochemical properties of niobium-doped $\mathrm{LiFePO}_{4} / \mathrm{C}$ synthesized by sol-gel method," Journal of the Chinese Chemical Society, vol. 65, no. 8, pp. 977-981, 2018.

[14] S. Okada, S. Sawa, M. Egashira, J. Yamaki, and M. Tabuchi, "Cathode properties of phospho-olivine $\mathrm{LiMPO}_{4}$ for lithium secondary batteries," Journal of Power Sources, vol. 97-98, pp. 430-432, 2001.

[15] Y. Yang, X.-Z. Liao, Z.-F. Ma, B.-F. Wang, L. He, and Y.-S. He, "Superior high-rate cycling performance of $\mathrm{LiFePO}_{4} / \mathrm{C}-\mathrm{PPy}$ composite at $55^{\circ} \mathrm{C}$," Electrochemistry Communications, vol. 11, no. 6, pp. 1277-1280, 2009.

[16] G. Du, Y. Zhou, X. Tian, G. Wu, Y. Xi, and S. Zhao, "Highperformance $3 \mathrm{D}$ directional porous $\mathrm{LiFePO}_{4} / \mathrm{C}$ materials synthesized by freeze casting," Applied Surface Science, vol. 453, pp. 493-501, 2018.

[17] J. B. Bates, N. J. Dudney, G. R. Gruzalski et al., "Fabrication and characterization of amorphous lithium electrolyte thin films and rechargeable thin-film batteries," Journal of Power Sources, vol. 43, no. 1-3, pp. 103-110, 1993.

[18] F. Mattelaer, P. M. Vereecken, J. Dendooven, and C. Detavernier, "The influence of ultrathin amorphous ALD alumina and titania on the rate capability of anatase $\mathrm{TiO}_{2}$ and $\mathrm{LiMn}_{2} \mathrm{O}_{4}$ Lithium ion battery electrodes," Advanced Materials Interfaces, vol. 4, no. 13, pp. 1-11, 2017.

[19] C. M. Julien, A. Mauger, K. Zaghib, and H. Groult, "Comparative issues of cathode materials for Li-ion batteries," Inorganics, vol. 2, no. 1, pp. 132-154, 2014.

[20] S.-W. Lee, M.-S. Kim, J. H. Jeong et al., " $\mathrm{Li}_{3} \mathrm{PO}_{4}$ surface coating on Ni-rich $\mathrm{LiNi}_{0.6} \mathrm{Co}_{0.2} \mathrm{Mn}_{0.2} \mathrm{O}_{2}$ by a citric acid assisted sol-gel method: Improved thermal stability and high- voltage performance," Journal of Power Sources, vol. 360, pp. 206214, 2017.

[21] X. Xiong, Z. Wang, H. Guo, Q. Zhang, and X. Li, "Enhanced electrochemical properties of lithium-reactive $\mathrm{V}_{2} \mathrm{O}_{5}$ coated on the $\mathrm{LiNi}_{0.8} \mathrm{Co}_{0.1} \mathrm{Mn}_{0.1} \mathrm{O}_{2}$ cathode material for lithium ion batteries at $60^{\circ} \mathrm{C}, "$ Journal of Materials Chemistry A, vol. 1 , no. 4, pp. 1284-1288, 2013.

[22] M. K. Devaraju and I. Honma, "Hydrothermal and solvothermal process towards development of $\mathrm{LiMPO}_{4}(\mathrm{M}=\mathrm{Fe}, \mathrm{Mn})$ nanomaterials for lithium-ion batteries," Advanced Energy Materials, vol. 2, no. 3, pp. 284-297, 2012.

[23] P. Hou, H. Zhang, Z. Zi, L. Zhang, and X. Xu, "Core-shell and concentration-gradient cathodes prepared via coprecipitation reaction for advanced lithium-ion batteries," Journal of Materials Chemistry A, vol. 5, no. 9, pp. 42544279, 2017.
[24] Y. Liu, W. Zhang, Y. Zhu et al., "Architecturing hierarchical function layers on self-assembled viral templates as 3D nano-array electrodes for integrated $\mathrm{Li}$-ion microbatteries," Nano Letters, vol. 13, no. 1, pp. 293-300, 2013.

[25] C. Zhu, Y. Fu, and Y. Yu, "Designed nanoarchitectures by electrostatic spray deposition for energy storage," Advanced Materials, vol. 31, no. 1, pp. 1-25, 2019.

[26] W. Lu, L. Liang, X. Sun et al., "Recent progresses and development of advanced atomic layer deposition towards highperformance Li-ion batteries," Nanomaterials, vol. 7, no. 10, p. 325, 2017.

[27] W. Pfleging, "A review of laser electrode processing for development and manufacturing of lithium-ion batteries," Nano, vol. 7, no. 3, pp. 549-573, 2017.

[28] C. Chen, R. A. Eichel, and P. H. L. Notten, "Metal-organic chemical vapor deposition enabling all-solid-state Li-ion microbatteries: a short review," Journal of Electroceramics, vol. 38, no. 2-4, pp. 230-247, 2017.

[29] B. Yan, J. Liu, B. Song, P. Xiao, and L. Lu, "Li-rich thin film cathode prepared by pulsed laser deposition," Scientific Reports, vol. 3, no. 1, pp. 1-5, 2013.

[30] J. Joseph, A. T. Murdock, D. H. Seo, Z. J. Han, A. P. O. Mullane, and K. K. Ostrikov, "Plasma enabled synthesis and processing of materials for lithium-ion batteries," Advanced Materials Technologies, vol. 3, no. 9, pp. 1-19, 2018.

[31] J. B. Bates, N. J. Dudney, B. Neudecker, A. Ueda, and C. D. Evans, "Thin-film lithium and lithium-ion batteries," Solid State Ionics, vol. 135, no. 1-4, pp. 33-45, 2000.

[32] Y. N. Zhou, M. Z. Xue, and Z. W. Fu, "Nanostructured thin film electrodes for lithium storage and all-solid-state thinfilm lithium batteries," Journal of Power Sources, vol. 234, pp. 310-332, 2013.

[33] Y. Zhou and Z. W. Fu, "Nanostructured thin film electrode materials for lithium ion battery," Progress in Chemistry, vol. 23, pp. 337-348, 2011.

[34] J. Sun, K. Tang, X. Yu, H. Li, and X. Huang, "Needle-like $\mathrm{LiFePO}_{4}$ thin films prepared by an off-axis pulsed laser deposition technique," Thin Solid Films, vol. 517, no. 8, pp. 2618-2622, 2009.

[35] F. Sauvage, E. Baudrin, L. Gengembre, and J. M. Tarascon, "Effect of texture on the electrochemical properties of $\mathrm{LiFePO}_{4}$ thin films," Solid State Ionics, vol. 176, no. 23-24, pp. 1869-1876, 2005.

[36] J. Yan, X. Liu, and B. Li, "Recent progress in Li-rich layered oxides as cathode materials for Li-ion batteries," RSC Advances, vol. 4, no. 108, pp. 63268-63284, 2014.

[37] Z. Qi, J. Tang, J. Huang, D. Zemlyanov, V. G. Pol, and $\mathrm{H}$. Wang, " $\mathrm{Li}_{2} \mathrm{MnO}_{3}$ thin films with tilted domain structure as cathode for Li-ion batteries," ACS Applied Energy Materials, vol. 2, no. 5, pp. 3461-3468, 2019.

[38] S. Taminato, M. Hirayama, K. Suzuki et al., "Highly reversible capacity at the surface of a lithium-rich manganese oxide: a model study using an epitaxial film system," Chem Commun (Camb), vol. 51, no. 9, pp. 1673-1676, 2015.

[39] V. K. Vendra, T. Q. Nguyen, A. K. Thapa, J. B. Jasinski, and M. K. Sunkara, "Scalable synthesis and surface stabilization of $\mathrm{Li}_{2} \mathrm{MnO}_{3} \mathrm{NWs}$ as high rate cathode materials for Li-ion batteries," RSC Advances, vol. 5, no. 46, pp. 36906-36912, 2015.

[40] M. Cheng, W. Tang, Y. Sun, and K. Zhu, "Electrochemical properties of $\mathrm{Li}_{2} \mathrm{MnO}_{3}$ nanocrystals synthesized using a 
hydrothermal method," RSC Advances, vol. 5, no. 87, pp. 71088-71094, 2015.

[41] H. Xia, Y. Wan, W. Assenmacher, W. Mader, G. Yuan, and L. Lu, "Facile synthesis of chain-like $\mathrm{LiCoO}_{2}$ nanowire arrays as three-dimensional cathode for microbatteries," NPG Asia Materials, vol. 6, no. 9, article e126, 2014.

[42] K. Senthil, G. Kwak, and K. Yong, "Fabrication of superhydrophobic vanadium pentoxide nanowires surface by chemical modification," Applied Surface Science, vol. 258, no. 19, pp. 7455-7459, 2012.

[43] M. Prześniak-Welenc, N. A. Szreder, A. Winiarski et al., "Electrical conductivity and relaxation processes in $\mathrm{V}_{2} \mathrm{O}_{5}$ nanorods prepared by sol-gel method," Physica Status Solidi (b), vol. 252, no. 9, pp. 2111-2116, 2015.

[44] V. Goyal, N. Choudhary, K. Singh, and D. Kaur, "Structural and optical properties of (001)-oriented vanadium pentoxide nanorods," Nanomaterials and Energy, vol. 4, no. 1, pp. 5463, 2015.

[45] C. H. Chen, E. M. Kelder, and J. Schoonman, "Unique porous $\mathrm{LiCoO}_{2}$ thin layers prepared by electrostatic spray deposition," Journal of Materials Science, vol. 31, no. 20, pp. 54375442, 1996.

[46] J. Ma and Q. Z. Qin, "Electrochemical performance of nanocrystalline $\mathrm{LiMPO}_{4}$ thin-films prepared by electrostatic spray deposition," Journal of Power Sources, vol. 148, pp. 66-71, 2005.

[47] D. Shu, K. Y. Chung, W. I. Cho, and K. B. Kim, "Electrochemical investigations on electrostatic spray deposited $\mathrm{LiMn}_{2} \mathrm{O}_{4}$ films," Journal of Power Sources, vol. 114, pp. 253-263, 2003.

[48] C. H. Chen, A. A. J. Buysman, E. M. Kelder, and J. Schoonman, "Fabrication of $\mathrm{LiCoO}_{2}$ thin film cathodes for rechargeable lithium battery by electrostatic spray pyrolysis," Solid State Ionics, vol. 80, no. 1-2, pp. 1-4, 1995.

[49] Y. T. Kim, S. Gopukumar, K. B. Kim, and B. W. Cho, "Performance of electrostatic spray-deposited vanadium pentoxide in lithium secondary cells," Journal of Power Sources, vol. 117, no. 1-2, pp. 110-117, 2003.

[50] J. L. Shui, G. S. Jiang, S. Xie, and C. H. Chen, “Thin films of lithium manganese oxide spinel as cathode materials for secondary lithium batteries," Electrochimica Acta, vol. 49, no. 13, pp. 2209-2213, 2004.

[51] U. Lafont, A. Anastasopol, E. Garcia-Tamayo, and E. Kelder, "Electrostatic spray pyrolysis of $\mathrm{LiNi}_{0.5} \mathrm{Mn}_{1.5} \mathrm{O}_{4}$ films for 3D Li-ion microbatteries," Thin Solid Films, vol. 520, no. 9, pp. 3464-3471, 2012.

[52] S. Wang, S. Li, Y. Sun, X. Feng, and C. Chen, "Three-dimensional porous $\mathrm{V}_{2} \mathrm{O}_{5}$ cathode with ultra high rate capability," Energy \& Environmental Science, vol. 4, no. 8, pp. 28542857, 2011.

[53] S. Koike and K. Tatsumi, "Preparation and performances of highly porous layered $\mathrm{LiCoO}_{2}$ films for lithium batteries," Journal of Power Sources, vol. 174, no. 2, pp. 976-980, 2007.

[54] J. Mosa, M. Aparicio, A. Durán, C. Laberty-Robert, and C. Sanchez, "Nanocrystalline mesoporous $\mathrm{LiFePO}_{4}$ thinfilms as cathodes for Li-ion microbatteries," Journal of Materials Chemistry A, vol. 2, no. 9, pp. 3038-3046, 2014.

[55] A. Yamada, H. Koizumi, N. Sonoyama, and R. Kanno, "Phase change in $\mathrm{Li}_{x} \mathrm{FePO}_{4}$," Electrochemical and Solid-State Letters, vol. 8, no. 8, pp. A409-A413, 2006.

[56] S. W. Oh, S.-T. Myung, H. J. Bang, C. S. Yoon, K. Amine, and Y.-K. Sun, "Nanoporous structured $\mathrm{LiFePO}_{4}$ with spherical microscale particles having high volumetric capacity for lithium batteries," Electrochemical and Solid-State Letters, vol. 12, no. 9, p. A181, 2009.

[57] B. G. Park, S. Kim, I. D. Kim, and Y. J. Park, "Structural and electrochemical performance of three-dimensional $\mathrm{LiMn}_{2} \mathrm{O}_{4}$ thin film," Journal of Materials Science, vol. 45, no. 14, pp. 3947-3953, 2010.

[58] C. H. Mi, Y. X. Cao, X. G. Zhang, X. B. Zhao, and H. L. Li, "Synthesis and characterization of $\mathrm{LiFePO}_{4} /(\mathrm{Ag}+\mathrm{C})$ composite cathodes with nano-carbon webs," Powder Technology, vol. 181, no. 3, pp. 301-306, 2008.

[59] D. Yu, Y. Qiao, X. Zhou et al., "Mica-like vanadium pentoxide-nanostructured thin film as high-performance cathode for lithium-ion batteries," Journal of Power Sources, vol. 266, pp. 1-6, 2014.

[60] H. Xia, Q. Xia, B. Lin, J. Zhu, J. K. Seo, and Y. S. Meng, "Selfstanding porous $\mathrm{LiMn}_{2} \mathrm{O}_{4}$ nanowall arrays as promising cathodes for advanced 3D microbatteries and flexible lithium-ion batteries," Nano Energy, vol. 22, pp. 475-482, 2016.

[61] M. Bettge, S. Y. Ryu, S. MacLaren et al., "Hierarchically textured $\mathrm{Li}_{x} \mathrm{Mn}_{2-y} \mathrm{O}_{4}$ thin films as positive electrodes for lithium-ion batteries," Journal of Power Sources, vol. 206, pp. 288-294, 2012.

[62] M. Bettge, S. MacLaren, S. Burdin et al., "Low-temperature vapour-liquid-solid (VLS) growth of vertically aligned silicon oxide nanowires using concurrent ion bombardment," Nanotechnology, vol. 20, no. 11, p. 115607, 2009.

[63] G. P. Pandey, S. A. Klankowski, T. Liu, J. Wu, and J. Li, "Toward highly stable solid-state unconventional thin-film battery- supercapacitor hybrid devices: Interfacing vertical core-shell array electrodes with a gel polymer electrolyte," Journal of Power Sources, vol. 342, pp. 1006-1016, 2017.

[64] M. M. Shaijumon, E. Perre, B. Daffos, P. L. Taberna, J. M. Tarascon, and P. Simon, "Nanoarchitectured 3D cathodes for Li-ion microbatteries," Advanced Materials, vol. 22, no. 44, pp. 4978-4981, 2010.

[65] E. Perre, L. Nyholm, T. Gustafsson, P. L. Taberna, P. Simon, and K. Edström, "Direct electrodeposition of aluminium nano-rods," Electrochemistry Communications, vol. 10, no. 10, pp. 1467-1470, 2008.

[66] H. Yim, W. Y. Kong, S. J. Yoon et al., "Three-dimensional hemisphere-structured $\mathrm{LiSn}_{0.0125} \mathrm{Mn}_{1.975} \mathrm{O}_{4}$ thin-film cathodes," Electrochemistry Communications, vol. 43, pp. 36-39, 2014.

[67] F. Mattelaer, K. Geryl, G. Rampelberg, J. Dendooven, and C. Detavernier, "Amorphous and crystalline vanadium oxides as high-energy and high-power cathodes for threedimensional thin-film Lithium ion batteries," ACS Applied Materials \& Interfaces, vol. 9, no. 15, pp. 13121-13131, 2017.

[68] R. F. Balderas-Valadez, E. E. Antúnez, S. F. Olive-Méndez et al., "Porous silicon pillar and bilayer structure as a nucleation center for the formation of aligned vanadium pentoxide nanorods," Ceramics International, vol. 43, no. 11, pp. 8023-8030, 2017.

[69] J. Cai, Q. Sun, and X. Meng, "Novel nanostructured materials by atomic and molecular layer deposition," AIMS Materials Science, vol. 5, no. 5, pp. 957-999, 2018.

[70] M. Mäntymäki, M. Ritala, and M. Leskelä, "Metal fluorides as lithium-ion battery materials: an atomic layer deposition perspective," Coatings, vol. 8, no. 8, p. 277, 2018. 
[71] K. Gerasopoulos, E. Pomerantseva, M. McCarthy et al., "Hierarchical three-dimensional microbattery electrodes combining bottom-up self-assembly and top-down micromachining," ACS Nano, vol. 6, no. 7, pp. 6422-6432, 2012.

[72] Y. H. Ding, H. M. Ren, Y. Y. Huang, F. H. Chang, and P. Zhang, "Three-dimensional graphene/ $/ \mathrm{LiFePO}_{4}$ nanostructures as cathode materials for flexible lithium-ion batteries," Materials Research Bulletin, vol. 48, no. 10, pp. 3713-3716, 2013.

[73] J. Z. Wang, L. Lu, M. Lotya et al., "Development of $\mathrm{MoS}_{2}$-CNT composite thin film from layered $\mathrm{MoS}_{2}$ for lithium batteries," Advanced Energy Materials, vol. 3, no. 6, pp. 798-805, 2013.

[74] F. S. Gittleson, D. Hwang, W. H. Ryu et al., "Ultrathin nanotube/nanowire electrodes by spin-spray layer-by-layer assembly: a concept for transparent energy storage," ACS Nano, vol. 9, no. 10, pp. 10005-10017, 2015.

[75] K. H. Seng, J. Liu, Z. P. Guo, Z. X. Chen, D. Jia, and H. K. Liu, "Free-standing $\mathrm{V}_{2} \mathrm{O}_{5}$ electrode for flexible lithium ion batteries," Electrochemistry Communications, vol. 13, no. 5, pp. 383-386, 2011.

[76] Y. Zhang, J. Lai, Y. Gong et al., "A safe high-performance allsolid-state Lithium-vanadium battery with a freestanding $\mathrm{V}_{2} \mathrm{O}_{5}$ nanowire composite paper cathode," ACS Applied Materials \& Interfaces, vol. 8, no. 50, pp. 34309-34316, 2016.

[77] M. Sathiya, A. S. Prakash, K. Ramesha, J. M. Tarascon, and A. K. Shukla, " $\mathrm{V}_{2} \mathrm{O}_{5}$-anchored carbon nanotubes for enhanced electrochemical energy storage," Journal of the American Chemical Society, vol. 133, no. 40, pp. 1629116299, 2011.

[78] X. Chen, H. Zhu, Y. C. Chen et al., "MWCNT/ $/ \mathrm{V}_{2} \mathrm{O}_{5}$ core/shell sponge for high areal capacity and power density Li-ion cathodes," ACS Nano, vol. 6, no. 9, pp. 7948-7955, 2012.

[79] E. Brown, J. Acharya, G. P. Pandey, J. Wu, and J. Li, "Highly stable three lithium insertion in thin $\mathrm{V}_{2} \mathrm{O}_{5}$ Shells on vertically aligned carbon nanofiber arrays for ultrahigh-capacity lithium ion battery cathodes," Advanced Materials Interfaces, vol. 3, no. 23, pp. 1-11, 2016.

[80] E. Brown, S. H. Park, A. Elangovan et al., "Facilitating high-capacity $\mathrm{V}_{2} \mathrm{O}_{5}$ cathodes with stable two and three $\mathrm{Li}^{+}$insertion using a hybrid membrane structure consisting of amorphous $\mathrm{V}_{2} \mathrm{O}_{5}$ shells coaxially deposited on electrospun carbon nanofibers," Electrochimica Acta, vol. 269, pp. 144-154, 2018.

[81] M. Chen, X. Liang, F. Wang, D. Xie, G. Pan, and X. Xia, "Selfsupported $\mathrm{VO}_{2}$ arrays decorated with $\mathrm{N}$-doped carbon as an advanced cathode for lithium-ion storage," Journal of Materials Chemistry A, vol. 7, no. 12, pp. 6644-6650, 2019.

[82] N. Li, Z. Chen, W. Ren, F. Li, and H.-M. Cheng, "Flexible graphene-based lithium ion batteries with ultrafast charge and discharge rates," Proceedings of the National Academy of Sciences, vol. 109, no. 43, pp. 17360-17365, 2012.

[83] H. Ma, J. Xiang, and X. Xia, "Graphene foam supported $\mathrm{LiFePO}_{4}$ nanosheets composite as advanced cathode for lithium ion batteries," Materials Research Bulletin, vol. 101, pp. 205-209, 2018.

[84] H. C. M. Knoops, M. E. Donders, M. C. M. van de Sanden, P. H. L. Notten, and W. M. M. Kessels, "Atomic layer deposition for nanostructured Li-ion batteries," Journal of Vacuum Science \& Technology A: Vacuum, Surfaces, and Films, vol. 30, no. 1, article 010801, 2011.
[85] K. B. Gandrud, Thin Film Materials for Li-ion Batteries Made by Atomic Layer Deposition [Ph.D. thesis], 2014.

[86] L. Ma, R. B. Nuwayhid, T. Wu, Y. Lei, K. Amine, and J. Lu, "Atomic layer deposition for lithium-based batteries," Advanced Materials Interfaces, vol. 3, no. 21, 2016.

[87] R. Kohler, P. Smyrek, S. Ulrich, V. Trouillet, and W. Pfleging, "Patterning and annealing of nanocrystalline $\mathrm{LiCoO}_{2}$ thin films," Journal of Optoelectronics and Advanced Materials, vol. 12, pp. 547-552, 2010.

[88] J. Pröll, R. Kohler, C. Adelhelm et al., "Laser modification and characterization of Li-Mn-O thin film cathodes for lithiumion batteries," Laser-based Micro- and Nanopackaging and Assembly V, vol. 7921, article 79210Q, 2011.

[89] J. Pröll, R. Kohler, M. Torge et al., "Laser-adjusted threedimensional Li-Mn-O cathode architectures for secondary lithium-ion cells," Laser-based Micro- and Nanopackaging and Assembly VI, vol. 8244, article 82440S, 2012.

[90] R. Kohler, J. Proell, M. Bruns, S. Ulrich, H. J. Seifert, and W. Pfleging, "Conical surface structures on model thin-film electrodes and tape-cast electrode materials for lithium-ion batteries," Applied Physics A: Materials Science \& Processing, vol. 112, no. 1, pp. 77-85, 2013.

[91] C. Hudaya, M. Halim, J. Pröll et al., “A polymerized C ${ }_{60}$ coating enhancing interfacial stability at three-dimensional $\mathrm{LiCoO}_{2}$ in high-potential regime," Journal of Power Sources, vol. 298, pp. 1-7, 2015.

[92] J. Pröll, R. Kohler, A. Mangang et al., "Diode laser heat treatment of lithium manganese oxide films," Applied Surface Science, vol. 258, no. 12, pp. 5146-5152, 2012.

[93] S. R. Li, S. Y. Ge, Y. Qiao et al., "Three-dimensional porous $\mathrm{Fe}_{0.1} \mathrm{~V}_{2} \mathrm{O}_{5.15}$ thin film as a cathode material for lithium ion batteries," Electrochimica Acta, vol. 64, pp. 81-86, 2012.

[94] N. F. Uvarov, "Estimation of composites conductivity using a general mixing rule," Solid State Ionics, vol. 136-137, no. 1-2, pp. 1267-1272, 2000.

[95] Y. Xia and M. Yoshio, "Studies on Li-Mn-O spinel system (obtained from melt-impregnation method) as a cathode for $4 \mathrm{~V}$ lithium batteries Part IV. High and low temperature performance of $\mathrm{LiMn}_{2} \mathrm{O}_{4}$," Journal of Power Sources, vol. 66, pp. 129-133, 1997.

[96] A. R. Armstrong, M. Holzapfel, P. Novák et al., "Demonstrating oxygen loss and associated structural reorganization in the lithium battery cathode $\mathrm{Li}\left[\mathrm{Ni}_{0.2} \mathrm{Li}_{0.2} \mathrm{Mn}_{0.6}\right] \mathrm{O}_{2}$," Journal of the American Chemical Society, vol. 128, no. 26, pp. 8694-8698, 2006.

[97] T. Teranishi, N. Katsuji, K. Chajima et al., "Low-temperature high-rate capabilities of lithium batteries via polarizationassisted ion pathways," Advanced Electronic Materials, vol. 4, no. 4, pp. 1-7, 2018.

[98] J. Song, S. Jacke, D. Becker, and R. Hausbrand, "Stabilization of thin film $\mathrm{LiCoO}_{2}$ electrode by LiPON coating," Electrochemical and Solid-State Letters, vol. 14, no. 2, pp. A11-A13, 2011.

[99] Y. Kobayashi, H. Miyashiro, K. Takei et al., "5 V class all-solid-state composite lithium battery with $\mathrm{Li}_{3} \mathrm{PO}_{4}$ coated $\mathrm{LiNi}_{0.5} \mathrm{Mn}_{1.5} \mathrm{O}_{4}$," Journal of the Electrochemical Society, vol. 150, no. 12, p. A1577, 2003.

[100] I. Belharouak, C. Johnson, and K. Amine, "Synthesis and electrochemical analysis of vapor-deposited carbon-coated $\mathrm{LiFePO}_{4}$," Electrochemistry Communications, vol. 7, no. 10, pp. 983-988, 2005. 
[101] A. Bünting, S. Uhlenbruck, D. Sebold, H. P. Buchkremer, and R. Vaßen, "Three-dimensional, fibrous lithium iron phosphate structures deposited by magnetron sputtering," ACS Applied Materials \& Interfaces, vol. 7, no. 40, pp. 2259422600, 2015.

[102] K. Xie, P. Wu, Y. Zhou et al., "Nitrogen-doped carbonwrapped porous single-crystalline $\mathrm{CoO}$ nanocubes for highperformance lithium storage," ACS Applied Materials \& Interfaces, vol. 6, no. 13, pp. 10602-10607, 2014.

[103] Z. Ding, L. Zhao, L. Suo et al., "Towards understanding the effects of carbon and nitrogen-doped carbon coating on the electrochemical performance of $\mathrm{Li}_{4} \mathrm{Ti}_{5} \mathrm{O}_{12}$ in lithium ion batteries: a combined experimental and theoretical study," Physical Chemistry Chemical Physics, vol. 13, no. 33, pp. 1512715133, 2011.

[104] D. Xie, X. Xia, Y. Zhong et al., "Exploring advanced sandwiched arrays by vertical graphene and $\mathrm{N}$-doped carbon for enhanced sodium storage," Advanced Energy Materials, vol. 7, no. 3, 2017.

[105] G. X. Pan, F. Cao, Y. J. Zhang, and X. H. Xia, "Integrated carbon cloth supported $\mathrm{LiFePO}_{4} / \mathrm{N}-\mathrm{C}$ films as high-performance cathode for lithium ion batteries," Materials Research Bulletin, vol. 98, pp. 70-76, 2018.

[106] X. Xia, D. Chao, C. F. Ng et al., "VO ${ }_{2}$ nanoflake arrays for supercapacitor and Li-ion battery electrodes: performance enhancement by hydrogen molybdenum bronze as an efficient shell material," Materials Horizons, vol. 2, no. 2, pp. 237-244, 2015.

[107] Z.-B. Zhou, M. Takeda, T. Fujii, and M. Ue, "Li $\left[\mathrm{C}_{2} \mathrm{~F}_{5} \mathrm{BF}_{3}\right]$ as an electrolyte salt for $4 \mathrm{~V}$ class lithium-ion cells," Journal of the Electrochemical Society, vol. 152, no. 2, p. A351, 2005.

[108] J. L. Tebbe, A. M. Holder, and C. B. Musgrave, "Mechanisms of $\mathrm{LiCoO}_{2}$ cathode degradation by reaction with HF and protection by thin oxide coatings," ACS Applied Materials \& Interfaces, vol. 7, no. 43, pp. 24265-24278, 2015.

[109] J. Liu, B. Wang, Q. Sun, R. Li, T. K. Sham, and X. Sun, "Atomic layer deposition of hierarchical CNTs@FePO architecture as a 3D electrode for lithium-ion and sodiumion batteries," Advanced Materials Interfaces, vol. 3, no. 21, 2016.

[110] S. Kim, J. Liu, K. Sun, J. Wang, S. J. Dillon, and P. V. Braun, "Improved performance in $\mathrm{FeF}_{2}$ conversion cathodes through use of a conductive $3 \mathrm{D}$ scaffold and $\mathrm{Al}_{2} \mathrm{O}_{3}$ ALD coating," Advanced Functional Materials, vol. 27, no. 35, pp. 1-8, 2017.

[111] Z. Chen, Y. Qin, K. Amine, and Y. K. Sun, "Role of surface coating on cathode materials for lithium-ion batteries," Journal of Materials Chemistry, vol. 20, no. 36, pp. 7606-7612, 2010.

[112] K.-F. Chiu, "Optimization of synthesis process for carbonmixed $\mathrm{LiFePO}_{4}$ composite thin-film cathodes deposited by bias sputtering," Journal of the Electrochemical Society, vol. 154, no. 2, p. A129, 2007.

[113] K.-F. Chiu, H. Y. Tang, and B. S. Lin, "High conductivity $\mathrm{LiFePO}_{4} / \mathrm{C}$ composite thin films with Ti underlayers deposited by radio frequency sputtering," Journal of the Electrochemical Society, vol. 154, no. 4, p. A364, 2007.

[114] Z. G. Lu, M. F. Lo, and C. Y. Chung, "Pulse laser deposition and electrochemical characterization of $\mathrm{LiFePO}_{4} / \mathrm{C}$ composite thin films," Journal of Physical Chemistry C, vol. 112, no. 17, pp. 7069-7078, 2008.
[115] N. Zhou, E. Uchaker, Y. Y. Liu, S. Q. Liu, Y. N. Liu, and G. Z. Cao, "Effect of carbon content on electrochemical performance of $\mathrm{LiFePO}_{4} / \mathrm{C}$ thin film cathodes," International Journal of Electrochemical Science, vol. 7, pp. 12633-12645, 2012.

[116] Z. G. Lu, H. Cheng, M. F. Lo, and C. Y. Chung, "Pulsed laser deposition and electrochemical characterization of $\mathrm{LiFePO}_{4}$ Ag composite thin films," Advanced Functional Materials, vol. 17, no. 18, pp. 3885-3896, 2007.

[117] A. Eftekhari, "Electrochemical deposition and modification of $\mathrm{LiFePO}_{4}$ for the preparation of cathode with enhanced battery performance," Journal of the Electrochemical Society, vol. 151, no. 11, p. A1816, 2004.

[118] A. Eftekhari, "Mixed-metals codeposition as a novel method for the preparation of $\mathrm{LiMn}_{2} \mathrm{O}_{4}$ electrodes with reduced capacity fades," Journal of the Electrochemical Society, vol. 150, no. 7, p. A966, 2003.

[119] A. Eftekhari, "Electrochemical performance and cyclability of $\mathrm{LiFe}_{0.5} \mathrm{Mn}_{1.5} \mathrm{O}_{4}$ as a $5 \mathrm{~V}$ cathode material for lithium batteries," Journal of Power Sources, vol. 124, no. 1, pp. 182-190, 2003.

[120] F. Wu, G. Tan, J. Lu, R. Chen, L. Li, and K. Amine, "Stable nanostructured cathode with polycrystalline Li-deficient $\mathrm{Li}_{0.28} \mathrm{Co}_{0.29} \mathrm{Ni}_{0.30} \mathrm{Mn}_{0.20} \mathrm{O}_{2}$ for lithium-ion batteries," Nano Letters, vol. 14, no. 3, pp. 1281-1287, 2014.

[121] L. Nation, J. Li, C. James, Y. Qi, N. Dudney, and B. W. Sheldon, "In situ stress measurements during electrochemical cycling of lithium-rich cathodes," Journal of Power Sources, vol. 364, pp. 383-391, 2017.

[122] F. Huang, Z. W. Fu, and Q. Z. Qin, "A novel $\mathrm{Li}_{2} \mathrm{Ag}_{0.5} \mathrm{~V}_{2} \mathrm{O}_{5}$ composite film cathode for all-solid-state lithium batteries," Electrochemistry Communications, vol. 5, no. 3, pp. 262266, 2003.

[123] C. Jacob, J. Jian, Q. Su, S. Verkhoturov, R. Guillemette, and $\mathrm{H}$. Wang, "Electrochemical and structural effects of in situ $\mathrm{Li}_{2} \mathrm{O}$ extraction from $\mathrm{Li}_{2} \mathrm{MnO}_{3}$ for Li-ion batteries," ACS Applied Materials \& Interfaces, vol. 7, no. 4, pp. 2433-2438, 2015.

[124] C. Jacob, J. Jian, Y. Zhu, Q. Su, and H. Wang, “A new approach to investigate $\mathrm{Li}_{2} \mathrm{MnO}_{3}$ and $\mathrm{Li}\left(\mathrm{Ni}_{0.5} \mathrm{Mn}_{0.3} \mathrm{Co}_{0.2}\right) \mathrm{O}_{2}$ mixed phase cathode materials," Journal of Materials Chemistry A, vol. 2, no. 7, pp. 2283-2289, 2014.

[125] Z. Qi, J. Jian, J. Huang et al., " $\mathrm{LiNi}_{0.5} \mathrm{Mn}_{0.3} \mathrm{Co}_{0.2} \mathrm{O}_{2} / \mathrm{Au}$ nanocomposite thin film cathode with enhanced electrochemical properties," Nano Energy, vol. 46, pp. 290-296, 2018.

[126] Q. Shi, R. Hu, L. Ouyang, M. Zeng, and M. Zhu, "Highcapacity $\mathrm{LiV}_{3} \mathrm{O}_{8}$ thin-film cathode with a mixed amorphousnanocrystalline microstructure prepared by RF magnetron sputtering," Electrochemistry Communications, vol. 11, no. 11, pp. 2169-2172, 2009.

[127] Z. Yu, H. Xu, G. Zhu, D. L. Yan, and A. Yu, "Binary lithium titanate-titania nanocomposite thin-film electrodes for electrochemical energy storage," Energy Technology, vol. 4, no. 7, pp. 798-803, 2016.

[128] X. Yu, X. Chen, D. B. Buchholz et al., "Pulsed laser deposition and characterization of heteroepitaxial $\mathrm{LiMn}_{2} \mathrm{O}_{4} / \mathrm{La}_{0.5} \mathrm{Sr}_{0.5-}$ $\mathrm{CoO}_{3}$ bilayer thin films as model lithium ion battery cathodes," ACS Applied Nano Materials, vol. 1, no. 2, pp. 642-653, 2018. 